\title{
Ēriks Elksnis
}

\section{Tear Film Osmolarity of the Eye after Cataract Surgery}

Summary of the Doctoral Thesis for obtaining a doctoral degree (Ph.D.)

Sector - Clinical Medicine Sub-Sector - Ophthalmology

Riga, 2021 


\section{RīgA STRADIŇ̦̌ UNIVERSITY}

Ëriks Elksnis

ORCID 0000-0002-7899-8224

\section{Tear Film Osmolarity of the Eye after Cataract Surgery}

Summary of the Doctoral Thesis

for obtaining a doctoral degree (Ph.D.)

Sector - Clinical Medicine

Sub-Sector - Ophthalmology

Riga, 2021 
The Doctoral Thesis was developed at Rīga Stradiņš University, Latvia

Supervisor of the Doctoral Thesis:

Dr. med., Professor Guna Laganovska,

Rīga Stradiņš University, Latvia

Official Reviewers:

Dr. med., Professor Jānis Gardovskis,

Rīga Stradiņš University, Latvia

Dr. med., Associate Professor Rimvydas Ašoklis,

University of Vilnius, Lithuania

Dr. med., Associate Professor Kuldar Kaljurand,

University of Tartu, Estonia

Defence of the Doctoral Thesis will take place at the public session of the Promotion Council of Clinical Medicine on 1 December 2021 at 13.00 held online via Zoom platform

The Doctoral Thesis is available in RSU Library and on RSU website: https://www.rsu.lv/en/dissertations

Secretary of the Promotion Council:

Dr. med., Associate Professor Genādijs Trofimovičs 


\section{Table of Contents}

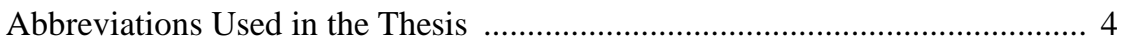

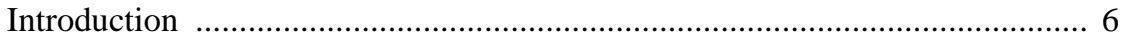

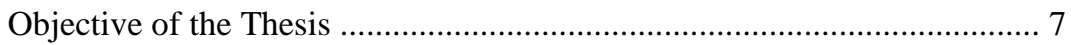

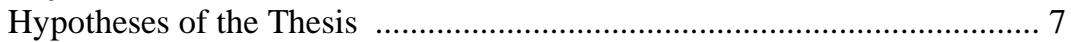

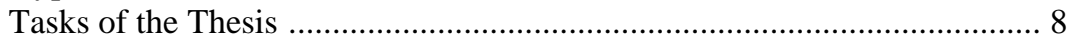

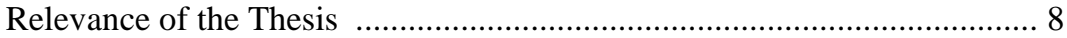

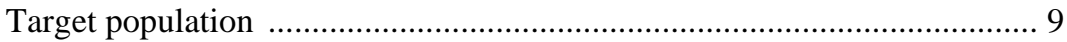

Place of execution, materials and technical resources ............................... 10

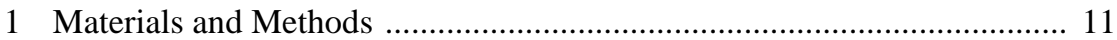

1.1 Distribution of research groups ..................................................... 11

1.2 Investigation group - eye with physiologically healthy ocular surface that has undergone cataract surgery .................................. 11

1.3 Control group - eye with a physiologically healthy ocular surface that has not been subject to cataract surgery ........................ 13

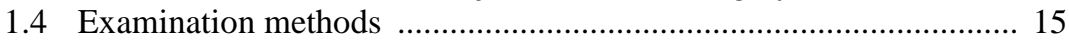

1.5 Description of tear film osmolarity test ........................................... 15

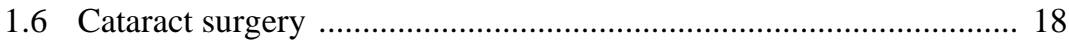

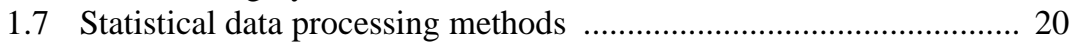

1.8 Description of patients included in the study .................................. 21

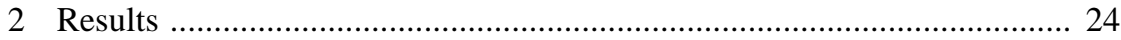

2.1 Dynamic change in tear film osmolarity after surgery .................... 24

2.2 Classification of osmolarity results by degree ................................ 28

2.3 Osmolarity one month after surgery .............................................. 31

2.4 Difference in osmolarity between eyes as an indicator of loss

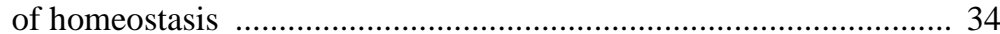

2.5 Association of osmolarity with patients' gender and age ................. 36

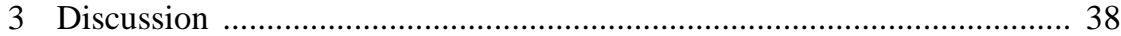

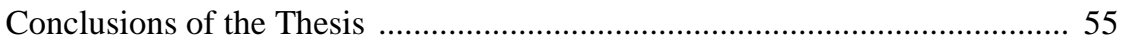

Approbation of the Research Work ........................................................... 57

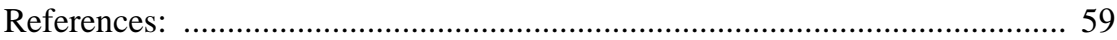

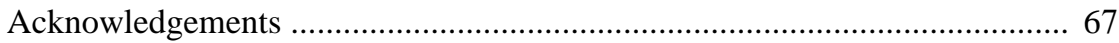




\section{Abbreviations Used in the Thesis}

\begin{tabular}{ll} 
ASCRS & American Society of Cataract and Refractive Surgery \\
DEWS & Dry Eye WorkShop \\
ESCRS & European Society of Cataract \& Refractive Surgeons \\
IOL & Intraocular lens \\
IQR & Interquartile range \\
M & Arithmetic mean \\
Max & Maximum value \\
Md & Mean deviation \\
Me & Median \\
mm & Millimetre / millimetres \\
Min & Minimum value \\
mOsm/L & Milliosmoles per litre \\
N & Quantity \\
NSAIDS & Non-steroid anti-inflammatory drugs \\
NY & New York \\
nl & Nanolitre \\
Osm & Osmole \\
OCT & Optical coherence tomography \\
OSDI & Ocular Surface Disease Index \\
p & p value \\
RSU & Rīga Stradinš University \\
s & Second/seconds \\
DES & Dry eye syndrome \\
Sol. & Solution \\
SPSS & Statistical Package for the Social Sciences \\
TNF $\alpha$ & Tumour necrosis factor $\alpha$ \\
TX & Texas \\
\hline &
\end{tabular}




$\begin{array}{ll}\begin{array}{ll}\text { USA } \\ \text { etc. }\end{array} & \text { The United States of America } \\ \pm \mathrm{SD} & \text { and others } \\ \% & \text { Standard deviation } \\ \mu \mathrm{m} / \mathrm{min} & \text { Percent } \\ \mu \mathrm{m} & \text { Micrometres per minute } \\ r & \text { Micrometre } \\ r_{s} & \text { Parametric Pearson's correlation coefficient } \\ \eta^{2} & \text { Non-parametric Pearson's correlation coefficient } \\ \varphi & \text { Statistical effect value } \\ Q & \text { Phi coefficient }\end{array}$




\section{Introduction}

More than 9.5 million cataract surgeries are performed worldwide every year, which ranks them among the most frequent surgical manipulations in the world (Foster, 2000). The main objective of the surgery is to improve the visual acuity of the patient by replacing the opacified, natural lens of a human with a clear, artificial, intraocular lens (Jain et al., 2019). Although cataract surgery is one of the most successfully performed medical manipulations worldwide (Norregaard et al., 2003), almost every cataract surgeon, during their career, has encountered a situation, where the main objective - improvement of vision - is reached, but the patient is still not satisfied, because they experience clinically significant discomfort in the operated eye on a daily basis (Adeeb M Rushdi, 2018). Often, the changes in the ocular surface, which are characterised by symptoms like grinding, itching, burning sensations, excessive lacrimation, etc. overshadow the surgically achieved improvement in visual acuity (Park et al., 2016). The aforementioned symptoms are caused by changes in the surface of the eye, principally, the haemostasis of the tear film (Ishrat et al., 2019). Although cataract surgery has been rapidly developing over the last century (Davis, 2016), despite the fact that multiple research studies have been conducted, (Gonzalez-Mesa et al., 2016) (B. Oncel et al., 2012) there is still no united opinion regarding the changes in the characteristic parameters during the post-surgical period. One of the parameters of ocular surface homeostasis, detailed research of which has become possible over recent years thanks to the development of diagnostic technologies and, which will receive a significant share of attention in this study, is osmolarity of tears (Baenninger et al., 2018). Attempts to research changes in tear osmolarity after cataract surgery that have been made to date involve long-term data, instead of early research - one month after surgery, when the subjective patient discomfort is considerably more pronounced (Ishrat et al., 2019). A considerable amount of attention is paid 
to the mutual correlation of symptoms and osmolarity (Potvin et al., 2015), which, nevertheless, fails to completely explain the changes in the osmolarity of tear film in the earlier stages after surgery on the healthy ocular surface. To perform in-depth research of osmolarity of ocular tear film, patients, who do not have eye-surface associated pathology, for instance, meibomitis, blepharitis or any other symptoms that are characteristic of dry eye syndrome, have been included in the study (Djalilian, 2018). Patients with pathologies or concomitant conditions that alter the osmolarity of the ocular surface were not included in the group. Thus, in terms of ocular surface condition, a completely "unaffected" group of patients could be obtained. This is especially challenging, since many other concomitant factors, for instance, the use of eye drops, glaucoma, pseudoexfoliation syndrome, diabetes mellitus, etc. are rather frequent in cataract

patients (Bourne et al., 2018) (Becker et al., 2018) (Fontana et al., 2017) (Davies et al., 2017) (Y.-C. Liu et al., 2017).

\section{Objective of the Thesis}

To determine the changes in eye tear film osmolarity on physiologically healthy ocular surfaces after cataract surgery during the post-surgical period.

\section{Hypotheses of the Thesis}

1 In the early postsurgical period after cataract surgery, the osmolarity of eye tear film in the operated eye is subject to statistically significant changes.

2 In the early postsurgical period after cataract surgery, the osmolarity of eye tear film does not statistically credibly change in unoperated eye.

3 The differences in the osmolarity of eye tear film between the study and control groups in the early post-surgical period were statistically significant. 


\section{Tasks of the Thesis}

1 To develop methodological inclusion and exclusion criteria to ensure that the patients with the least affected homeostasis of ocular surface are included in the study.

2 Among the included patients, to develop the study and control group. To include the eye of the patient that has undergone cataract surgery without complications in the study group, to include the eye, where the surgery was not performed - in the control group.

3 To perform tear osmolarity tests in both eyes by using the TearLab Osmolarity System metering device (TearLab Corporation, San Diego, California, the USA) in patients before the surgery, on the next morning after the surgery, one week after the surgery and one month after the surgery.

4 To compare the changes in tear osmolarity in the early post-surgical period in each group separately, as well as to compare the obtained results between the groups.

5 To perform the statistical analysis of the obtained data.

6 To evaluate the effect of cataract surgery on the homeostasis of the ocular surface, on the basis of the changes in the eye tear film in the early postsurgical period.

\section{Relevance of the Thesis}

As mentioned earlier in the work, the cataract surgery is one of the most common medical manipulations performed in the world (Norregaard et al., 2003), however, there is still no united opinion regarding the duration of the recovery period of the eye after surgery. None of the studies to date have analysed the changes in osmolarity of the healthy eye within one month after the cataract surgery, which could provide the community of ophthalmologists with in-depth understanding of the post-surgical healing processes after cataract surgery, as 
well as enable one to predict the provisional duration of the restoration period of ocular surface homeostasis. Over recent years, the osmolarity of tear film has become the principal marker for the evaluation of the health status of ocular surface (Baenninger et al., 2018). Literature has evidence regarding studies that prove the mutual link between osmolarity measurements and symptoms associated with dry eye syndrome (Gonzalez-Mesa et al., 2016) (Potvin et al., 2015), as well as the effect of osmolarity on the variability of intraocular lens and auto-refractometer measurements (Epitropoulos et al., 2015) (Ipek et al., 2018). In Latvia, most cataract patients are operated on at outpatient day care clinics by implanting a monofocal lens, which requires the application of reading glasses after surgery, or, in less frequent cases - glasses for distant vision. Without the awareness about the ocular surface recovery period and changes in osmolarity, a high risk of production of inappropriate eyeglasses exists, if the auto-refractometry measurements are made too early. Osmolarity tests are not routinely performed before cataract surgery, which creates an additional risk

of failing to reach target refraction in patients with high hyperosmolarity. The results and knowledge obtained during the study on the changes in tear film osmolarity and homeostasis would enable specialists to improve the care for cataract patients before surgery, as well as after the surgery, which provides the opportunity to avoid the presence of undesirable symptoms in the postsurgical period, incorrect implantation of intraocular lenses and prescription of inappropriate glasses.

\section{Target population}

The target population included 90 patients, who are characterised by a healthy ocular surface and lack of complaints associated with dry eye syndrome symptoms. The control group consisted of the same 90 patients, except the unoperated eye was subject to analysis. All participants of the study were patients 
of the Ophthalmology Day Care Clinic of Pauls Stradiņš Clinical University Hospital, who have undergone a scheduled cataract surgery and who have agreed to participate in the study by signing an individual consent form. The study was performed from 1 May 2017 until 21 December 2017.

In March 2017, the permit of the Ethics Committee of Rīga Stradin̄š University (RSU) for the conduct of the study, as well as the consent of the Education and Science Department of the Pauls Stradiņš Clinical University Hospital to perform the study at Pauls Stradiņš Clinical University Hospital were received.

\section{Place of execution, materials and technical resources}

Pauls Stradiņš Clinical University Hospital provided the premises, diagnostic equipment, as well as tools for the examination of patients and the performance of the surgery. The examination of patients before and after surgery and the determining of tear osmolarity was performed in the premises of the Ophthalmology Day Care Clinic of Pauls Stradiņš Clinical University Hospital by using the TearLab Osmolarity system metering device (TearLab Corporation, San Diego, California, the USA). Cataract surgeries were performed at the eye surgery block of Pauls Stradiņš Clinical University Hospital. 


\section{Materials and Methods}

\subsection{Distribution of research groups}

To reach the objective of the study, two patient groups were established:

1 Study group - patients with intact ocular surface without complaints characteristic of dry eye syndrome, diseases or concomitant factors that alter the osmolarity of ocular surface. The investigation group includes the eye that has been subject to cataract surgery.

2 Control group - the aforementioned patients with healthy ocular surface. The osmolarity was measured in the eye that was not subject to cataract surgery.

\subsection{Investigation group - eye with physiologically healthy ocular surface that has undergone cataract surgery.}

\section{Criteria for inclusion in the investigation group:}

1 Patients have arrived for scheduled cataract surgery.

2 Patients, who have been diagnosed with clinically significant opacity of the lens and in whom cataract surgery is indicated.

3 Patients, who have been subject to lens phacoemulsification with artificial lens implantation in the posterior chamber, which occurred without complications.

4 Patients, who did not have symptoms associated with ocular surface diseases prior to the surgery and who had never had a history of such symptoms.

5 Patients, who have not been diagnosed with diseases or concomitant factors that change the osmolarity of eye tear film. 


\section{Criteria for exclusion from the investigation group:}

1 Patients, who have not been diagnosed with clinically significant opacity of the lens and in whom cataract surgery was not indicated.

2 Patients, who have noted at least one symptom associated with ocular surface disease: feeling of dryness in the eye, burning or stinging sensation in the ocular surface, pain, itching, feeling of a foreign body, discharge/dried discharge on eyelashes, photophobia, hypersensitivity to wind, stuck eyelids/difficulty opening eyes in the morning, - were excluded from the investigation group.

3 Patients, who, prior to the surgery, were diagnosed with one or several pathologies characteristic of the ocular surface, which alter the osmolarity of tear film: blepharitis, meibomitis, dry eye syndrome.

4 Patients, who had been wearing contact lenses prior to the surgery.

5 Patients, who have been diagnosed with pterygium prior to the performance of surgery.

6 Patients, who have been diagnosed with pseudoexfoliation syndrome prior to surgery.

7 Patients, who have been diagnosed with diabetes mellitus prior to surgery.

8 Patients, who have been using any type of eye drops prior to the surgery.

9 Patients with a history of eye surgeries.

Patients, who arrived at the Ophthalmology Day Care Clinic of Pauls Stradiņš Clinical University Hospital for scheduled cataract surgery were included in the study group. Prior to the surgery, the patients were examined by a certified ophthalmologist, who confirmed the need to perform a cataract surgery. General ophthalmological examination was performed during the visit, history of the symptoms and duration thereof, other diseases that have occurred 
during the patient's lifetime, as well as medications used was collected. Upon the performance of the pre-surgical examination, the patients, who potentially conform to the healthy ocular surface profile, were selected, while patients with blepharitis, meibomitis and dry eye syndrome were excluded. Cataract patients, in whom pathologies or other concomitant factors that artificially affect the osmolarity of the eye tear film were also excluded from investigation group: contact lens wearers, regular users of eye drops, patients with pterygium, pseudoexfoliation syndrome and diabetes mellitus.

Prior to inclusion in the investigation group, the selected patients had to fill out the SAS modified symptom assessment scale (See Annex). In the event where the patient marked at least one existing symptom prior to the surgery, they were not included in the group.

The patients included in the investigation group were introduced to the nature and procedure of the study, as well as they were asked to fill out the consent form (See Annex).

Following the General Data Protection Regulation, to ensure anonymity, every patient who agreed to participate in the study received a code ensuring that the patient's name, surname, and personal identity number would not be displayed anywhere except for patient consent forms.

The study group included the eye of the patient that has been subject to cataract surgery.

\subsection{Control group - eye with a physiologically healthy ocular surface that has not been subject to cataract surgery}

The control group consisted of the same patients with a healthy ocular surface as a constant parameter for the analysis of the eye, which was not subject to the cataract surgery. The unoperated eye of the patient was examined prior to the surgery, and the compliance of the patient was evaluated by inclusion and 
exclusion criteria. Tests of the eye tear film osmolarity were performed for both eyes before and after the surgery, practically at the same time (with an interval of a few minutes).

\section{Criteria of inclusion in the control group:}

1 The patients, who have arrived for a scheduled cataract surgery.

2 Patients, who have been diagnosed with clinically significant opacity of the lens and in whom a cataract surgery is indicated.

3 Eye, where the cataract surgery was not performed.

4 Patients, who did not have symptoms associated with ocular surface diseases prior to the surgery and who had never had a history of such symptoms.

5 Patients, who have not been diagnosed with diseases or concomitant factors that change the osmolarity of eye tear film.

\section{Criteria of exclusion from the control group:}

1 Patients, who have not been diagnosed with clinically significant opacity of the lens and in whom cataract surgery was not indicated.

2 Patients, who marked at least one symptom associated with ocular surface disease, when filling out the pre-surgery questionnaire, were not included in the investigation group: burning, grinding sensation of ocular surface, feeling of a foreign body in the eye, itching, red eyeball colour, tiredness of eyes, photophobia, Increased lacrimation.

3 Patients, who, prior to the surgery, were diagnosed with one or several pathologies characteristic of ocular surface, which alter the osmolarity of tear film: blepharitis, meibomitis, dry eye syndrome.

4 Patients, who had been wearing contact lenses prior to the surgery.

5 Patients, who have been diagnosed with pterygium prior to the performance of surgery. 
6 Patients, who have been diagnosed with pseudoexfoliation syndrome prior to surgery.

7 Patients, who have been diagnosed with diabetes mellitus prior to surgery.

8 Patients, who have been using any type of eye drops prior to the surgery.

9 Patients with a history of eye surgeries.

\subsection{Examination methods}

\section{Tear film osmolarity test}

Tear osmolarity of the patients was determined by means of the TearLab Osmolarity System device (TearLab Corporation, San Diego, California, the USA). The test was performed on both eyes of patients included in the study prior to the surgery-before the mydriatic and anaesthetic drops were administered in order to exclude their effect on the osmolarity measurements of the tear film. The test was repeated on both eyes on the morning after the surgery, prior to the use of antibiotics and corticosteroids in the operated eye. The next measurement was performed approximately one week after cataract surgery, two hours after the last use of post-surgical eye drops. The last eye tear film osmolarity measurement was performed approximately one month after cataract surgery and, to exclude the effect of eye drops on the osmolarity of tear film, the test was performed at least two hours after the last use of eye drops.

\subsection{Description of tear film osmolarity test}

TearLab Osmolarity System metering device (TearLab Corporation, San Diego, California, the USA) has been designed to determine the osmolarity of human eye tear film. The device consists of a portable base with a display 
for the visualisation of measurement results, two testing pens, as well as disposable testing tips (Figure 1.1). It is an express diagnostic test, which displays the result within a couple of seconds after the collection of tear samples (TearLab Corporation, tearlab.com 2012).

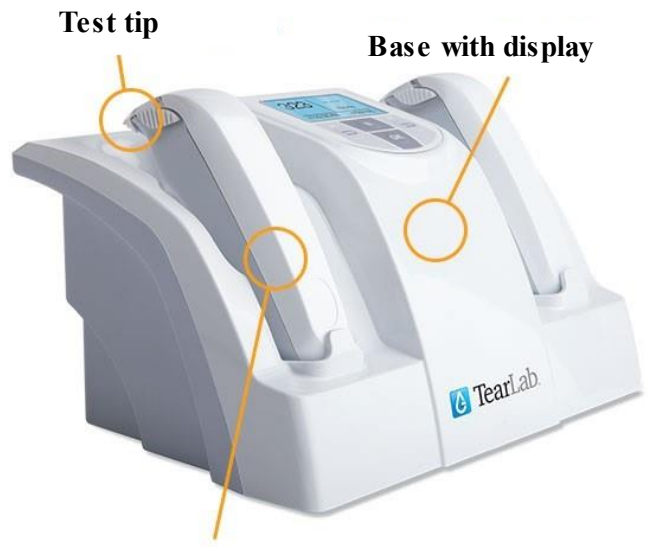

Test pen

Figure 1.1 TearLab Osmolarity System metering device (Piera Versura \& Campos, 2013) (tearlab.com)

Prior to the performance of the test, the patient is asked to sit down, slightly raise their chin to turn the face towards the ceiling and close their eyes three times, thus promoting the production of tears and the increase in the amount of testing material on the lower eyelid vault (Figure 1.2 A). A separate test pen is used for each eye. Prior to the performance of the measurement itself, a disposable test tip is removed from the sterile packaging and fixed on the test pen (Figure 1.3). Pursuant to the sound signal, that indicates that the test pen has recognised the testing tip, the performance of measurement is permitted. Outpatient examinations are always started with the right eye, however, within 
the framework of the study, the operated eye was always tested first, followed by testing of the unoperated eye. Before the amount of tears required for testing is collected, the patient is required to look upwards to avoid any opportunity of trauma to the cornea with the sharp point of the testing tip. To collect the tear sample for analysis, under manual and visual control, place the test pen, with the sharp tip, that contains a microscopic pump, which can accumulate $50 \mathrm{~nL}$ of tears in a container, directly above the lower eyelid in the lateral part thereof, where tear meniscus is situated without touching the skin of the eyelid or conjunctiva in order to exclude the effect of skin or conjunctival microscopic particles on the measurement results (Figure 1.2 B). When the test pen is installed with the tip in the required position, wait for the sound and light signal, which bears evidence that the required amount of eye tear film to perform the test has been reached $(\sim 50 \mathrm{~nL})$, (Figure 1.2 C - E). Connect the test pen with the connected tip with the base which will perform the measurement within a couple of seconds, and present the osmolarity of tear material on the display. Considering the fact that the contact with the ocular surface is minimal, no preventive use of antibiotic drops is required after the performance of the measurement (Piera Versura \& Campos, 2013) (tearlab.com).
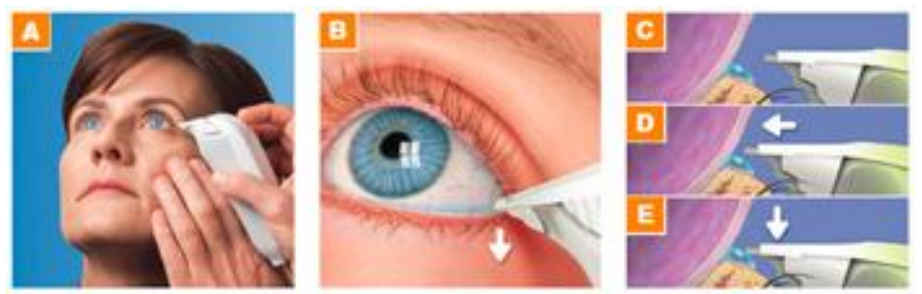

Figure 1.2 Collection of sample for tear osmolarity test: A) Head position of the patient, B) Placement of test pen, C) - E) Collection of tear sample (Piera Versura \& Campos, 2013) (tearlab.com) 

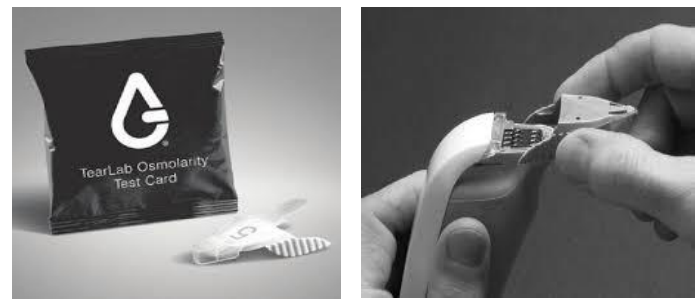

\section{Figure 1.3 The disposable tip of the TearLab Osmolarity System metering device and connecting it to the test pen \\ (Piera Versura \& Campos, 2013) (tearlab.com)}

\subsection{Cataract surgery}

The patients included in the study received local anaesthesia with Sol. Lidocine $2 \%$ and Sol. Bupivacaine $0.5 \%$ into the sub-tenon space. Prior to the surgery, during the preparation period, the patient received topical anaesthetic drops of Sol. Proxymetacaini $0.5 \%$ several times, as well as mydriatic agents Sol. Phenyleprini 5\% and Sol. Tropicamidi $0.5 \%$ to dilate the pupil. All surgeries were performed by the scientific supervisor of the Thesis, professor, Guna Laganovska. Phacoemulsification method was practised during the surgery. The disinfection of skin in the surgery site during surgery was performed by means of Sol. Chemisept $\mathrm{G}$ and a sterile film with an opening that is adjusted to ensure access to the area of the operated eye. An adhesive film was fixed to the skin of eyelids and eyelashes, which reduces the possibility of the skin and eyelash microflora entering the ocular surface. An opening was made in the area of the eye slit, which was fixed by means of an eyelid retractor. The eye slit was rinsed with Sol. Iodine 5\%. The solution was allowed to act for 30 seconds and was later rinsed with $10 \mathrm{ml}$ of balanced saline solution. After the treatment of the ocular surface, the anaesthesia of the sub-tenon space was performed with the aforementioned medications. After the preparation of the patient for surgery, a $2.8 \mathrm{~mm}$ wide incision on the temporal side was made and the anterior chamber of the eye was filled with viscoelastic material. In the upper nasal quadrant, 
a $15^{\circ}$ knife was used to make a paracentesis incision that is narrower than the temporal tunnel. It serves as the entrance gate for the tool - spatula. Capsulorexis forceps are used to create a round continuous opening in the anterior capsule of the lens through the temporal tunnel, which reaches approximately $5 \mathrm{~mm}$ in diameter. By placing the anterior chamber cannula between the lens capsule and layers of the lens, the lens was separated from the capsule of the lens, by slowly injecting the basal saline solution at a steady rate. The mobility of the lens and cortical layers was checked by means of rotating the lens with the help of a cannula. Phacoemulsification was performed by means of the Alcon Infiniti Vision System (Alcon, Fort Worth, TX, the USA) phaco-machine by dissolving the nucleus of the lens and suction thereof. The rest of the soft masses of the lens and subcapsular layers were evacuated by means of the aspiration-irrigation method. Prior to the insertion of the artificial intraocular lens, the pouch of the capsule was filled with viscoelastic material. The artificial lens was inserted through the temporal tunnel incision, which was prepared, folded and placed into the cartridge, which, in turn, was connected to the injector that allows controlled movement of the lens through the incision into the pouch of the capsule. The intraocular artificial lens was positioned and stabilised in the capsular pouch by means of a spatula. The previously injected viscoelastic material was rinsed from the anterior and posterior chamber, as well as from the capsular pouch. The corneal incisions were closed by means of the hydration method. Subconjunctival injection of Sol. Dexamethazoni and Sol. Gentamicine $0.2 \mathrm{ml}$ was performed. The eye slit was rinsed with Sol. Iodine 5\% solution and balanced saline solution, as well as DexaChlora ointment, which contains dexamethasone and chloramphenicol (Santen Oy, Japan), was applied into the eye slit. The eye was sealed with a sterile bandage. 
The recommendations regarding what must be observed after the surgery were repeatedly provided to the patient, and Maxitrol eye drops (Alcon, Fort Worth, TX, USA), which contain dexamethasone, neomycin sulphate, polymyxin $\mathrm{B}$, were prescribed in accordance with the scheme to ensure antibacterial and anti-inflammatory action.

\section{7 $\quad$ Statistical data processing methods}

All graphical images, calculation and statistical analysis were performed by using IBM SPSS (Statistical Package for the Social Sciences) Statistics 24 (IBM Corporation, Armonk, NY, the USA) software.

Normal distribution of data was checked by means of the KolmogorovSmirnov selection test. If data selection distribution conformed to normal distribution, the data were reflected as the mean value (M) and standard deviation $( \pm \mathrm{SD})$. Otherwise, the data were reflected as a median and interquartile range (IQR).

The statistical analysis of normal distribution data (parametric data): the mean values between the two separate groups were compared by using t-test. The changes for three and more paired groups were compared by using covariance analysis (Repeated measures ANCOVA). The age of patients was separated as a non-attributable potential variable. During covariance analysis of paired measurements, the Post-hoc (secondary) evaluation was performed by using Bonferroni correction. Covariance analysis $\eta^{2}$ was used for the assessment of statistical effect.

Statistical analysis of data with the values that did not conform to normal distribution (non-parametric data): the difference between two separate unpaired groups was determined by using the Mann-Whitney U-test, while the difference between two paired groups was evaluated by using the Wilcoxon signed-range test. 
Correlation analysis method was used for the research of mutual relations between quantitative variables. Depending on data distribution, either parametric Pearson $($ symbol $-r)$ or non-parametric Spearman $\left(s y m b o l-r_{s}\right)$ correlation analysis was used.

Both single factor and multifactor regression analysis was used for the evaluation of mutual influences of quantitative data.

The qualitative data were characterised as the number $(\mathrm{N})$ and percentage thereof (\%). McNemar's test was used for the analysis of paired qualitative data. Pearson chi square statistical test was used for the analysis of unpaired qualitative data in the cases where the quantity of expected frequencies was $>5$. If the amount of frequencies failed to meet the expectations, the Fisher exact test was used. The evaluation of the contingency table was based on the calculation of Odds ratio with a $95 \%$ confidence interval, as well as on the $\boldsymbol{\varphi}(P h i)$ coefficient for the evaluation of the statistical effect. It was categorised by value as follows: 0.1-0.3: weak; 0.31-0.5: medium; > 0.5 - significant.

Cochran-Mantel-Haensel test was used for the calculation of association between two qualitative characteristics (for the evaluation of differences in odds ratios) by separately assessing the effect of the potential mixing factor.

Cochran's Q test was used for the calculations of heterogeneity of more than two paired selections.

Bilateral $\mathrm{p}$ value, which is lower than $0.05(\mathrm{p}<0.05)$, was considered to be statistically significant for all statistical tests that were used in practice.

\subsection{Description of patients included in the study}

90 patients were included in the study, the youngest participant was 63 years old, while the oldest patient was 86 yearsold (age amplitude: 23 years). The average age of patients was $72.66 ; \mathrm{SD}=4.82$ years; age median: 72 years; modal or most frequently occurring age: 68 years. First age quartile: 69 years, 
third: 76 years; age interquartile range: 7 years. Histogram and box plot of patient age are provided in Figure 1.4.
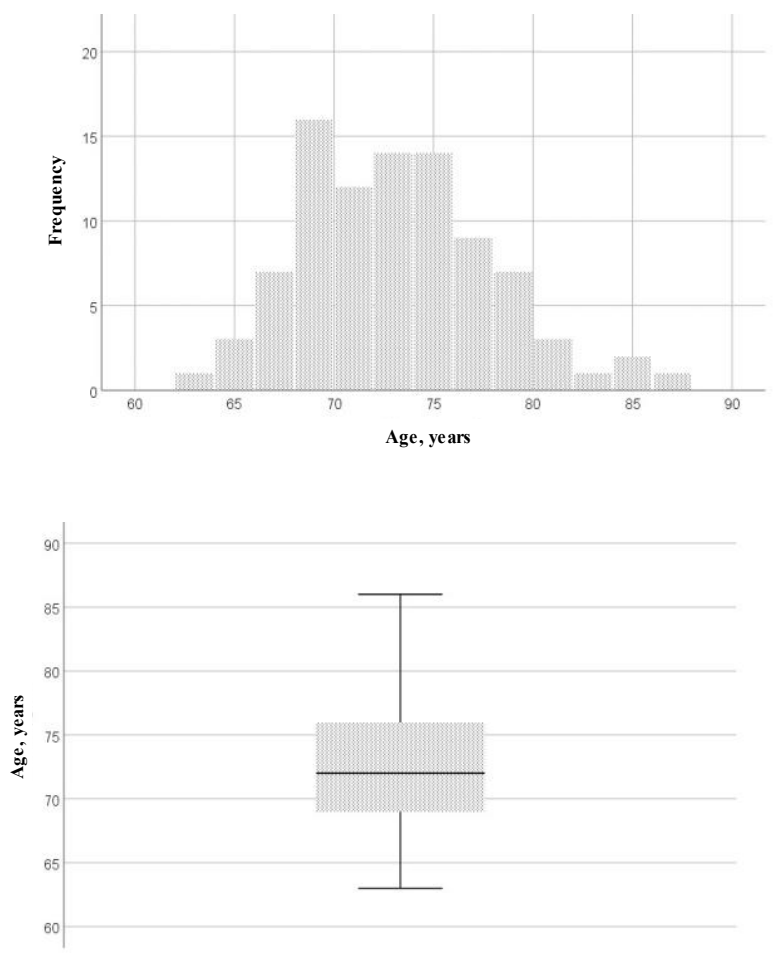

Figure 1.4 Patient age a) histogram, b) box plot

The participants of the study included 29 (32.2\%) men with the average age $(\mathrm{M}=71.41 ; \mathrm{SD}=4.35$ years $)$ and $61(67.8 \%)$ women $(\mathrm{M}=73.25 ; \mathrm{SD}=4.95$ years). Upon the comparison of the average age difference between men and women, no statistically significant difference was detected $(p=0.11)$. The histogram of male and female age is indicated in Figure 1.5. 


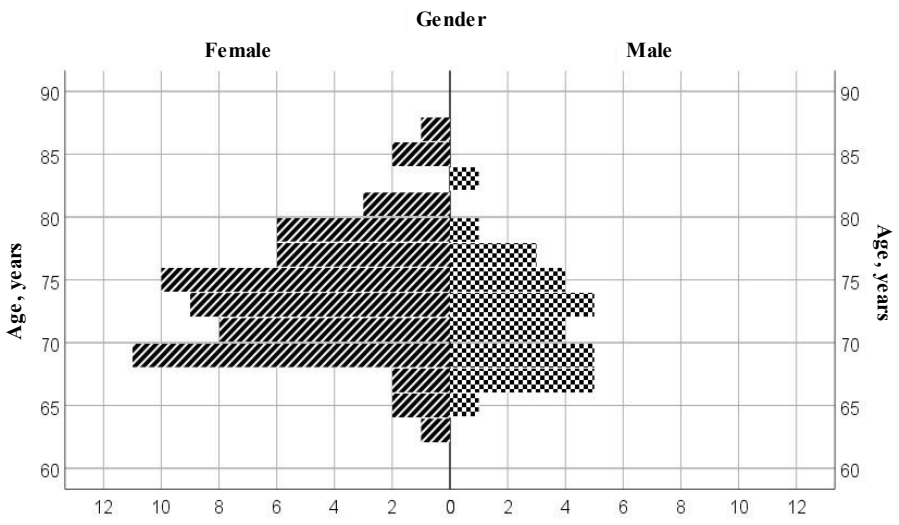

Figure 1.5 The histogram of men and women, who participated in the study 


\section{Results}

\subsection{Dynamic change in tear film osmolarity after surgery}

Both eyes of the patient were included in the study (a total of 180 eyes). The study group consisted of 90 eyes that have been subject to cataract surgery and the control group - 90 eyes that were not subject to surgery.

Upon the tests of tear film osmolarity before surgery in control $(\mathrm{M}=297.27 \mathrm{mOsm} / \mathrm{L} ; \mathrm{Me}=297.50 \mathrm{mOsm} / \mathrm{L} ; \mathrm{Q} 1-\mathrm{Q} 3: 289.75-305.00)$ and study groups $(\mathrm{M}=296.87 \mathrm{mOsm} / \mathrm{L} ; \quad \mathrm{Me}=297.00 \mathrm{mOsm} / \mathrm{L} ; \quad \mathrm{Q} 1-\mathrm{Q} 3$ : $287.0-304,25)$, it was established that the osmolarity did not have statistically significant differences (Mann-Whitney test, $\mathrm{p}=0.84$ ), see Figure 2.1.

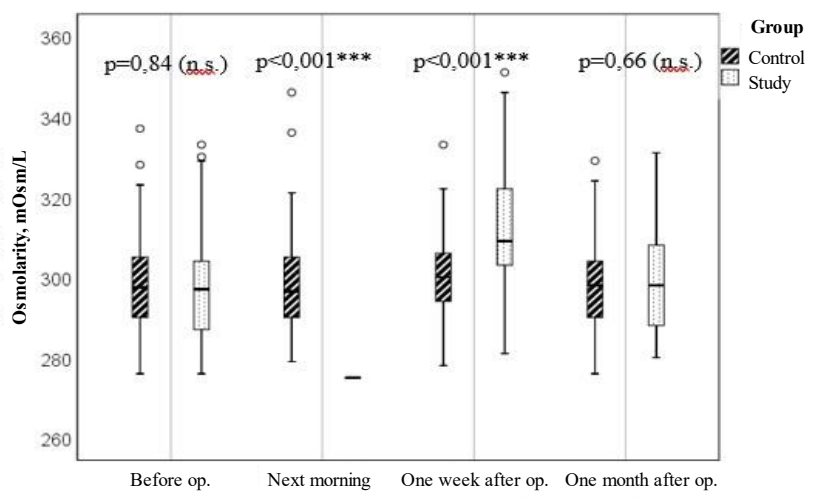

Figure 2.1 The box plot of eye tear film osmolarity in control and study groups before and after cataract surgery 
Table 2.1

Changes in osmolarity parameters in control and study groups over time

\begin{tabular}{|c|c|c|c|c|}
\hline Time & $\begin{array}{c}\text { Control group } \\
M( \pm S D) \\
\operatorname{Min}-\max \\
\operatorname{Md}(Q 1-Q 3) \\
\end{array}$ & $\begin{array}{c}\text { Study group } \\
M( \pm S D) \\
\operatorname{Min}-\max \\
\operatorname{Md}(Q 1-Q 3) \\
\end{array}$ & p value & $\begin{array}{c}\text { Scope } \\
\text { of effect }\end{array}$ \\
\hline $\begin{array}{l}\text { Before } \\
\text { surgery }\end{array}$ & $\begin{array}{l}297.27(11.81) \\
276-337 \\
297.50(289.75-305.00)\end{array}$ & $\begin{array}{l}296.87(12.68) \\
279-333 \\
297.00(287.00-304.25)\end{array}$ & 0.84 (n.s.) & 0.02 \\
\hline $\begin{array}{l}\text { Next } \\
\text { morning } \\
\text { after } \\
\text { surgery }\end{array}$ & $\begin{array}{l}298.43(11.80) \\
279-346 \\
296.50(290.00-305.25)\end{array}$ & $\begin{array}{l}275.00(0) \\
275-275 \\
275(275-275)\end{array}$ & $<0.001 * * *$ & - \\
\hline $\begin{array}{l}\text { One } \\
\text { week } \\
\text { after } \\
\text { surgery }\end{array}$ & $\begin{array}{l}299.78(10.77) \\
278-333 \\
300.00(293.50-306.00)\end{array}$ & $\begin{array}{l}31264(14.10) \\
281-351 \\
309.00(303.00-322.25)\end{array}$ & $<0.001 * * *$ & 0.65 \\
\hline $\begin{array}{l}\text { One } \\
\text { month } \\
\text { after } \\
\text { surgery }\end{array}$ & $\begin{array}{l}297.87(10.79) \\
276-329 \\
298.00(290.00-304.25)\end{array}$ & $\begin{array}{l}298.93(12.04) \\
280-331 \\
298.00(288.00-308.00)\end{array}$ & 0.66 (n.s.) & 0.04 \\
\hline
\end{tabular}

The osmolarity of eye tear film has dropped sharply in the study group on the morning that followed the surgery - it has fallen below the detection range of the TearLab metering device, namely, the tears have become hypo-osmolar. As mentioned earlier, the TearLab metering device is capable of registering the osmolarity of human tear film in the range from $275 \mathrm{mOsm} / \mathrm{L}$ to $400 \mathrm{mOsm} / \mathrm{L}$. In the morning of the day that followed the surgery, the measurements in operated eyes of all patients have returned the "Below Range" value, which means that the tears have become hypo-osmolar and osmolarity is below $275 \mathrm{mOsm} / \mathrm{L}$. The metering device has not been programmed to numerically measure such a low value. For the purposes of further numerical analysis of the results, the figure $275 \mathrm{mOsm} / \mathrm{L}$, which is the lowest possible measurement that can be registered by the TearLab metering device (Piera Versura \& Campos, 2013), was assumed as the average value of the investigation group in the morning of the day that followed the surgery. 
In the control group, the average value of eye tear film osmolarity on the morning that followed the surgery was $298.43 \mathrm{mOsm} / \mathrm{L}$. The observation can be made that no differences in osmolarity were detected between the control and study groups before surgery, while, in the morning of the post-surgical day, a statistically significant difference between both eyes was detected (Mann-Whitney test, $\mathrm{p}<0.001$ ) (Figure 2.1). One week after the surgery, a considerable increase in osmolarity was observed in the study group - to $312.64 \mathrm{mOsm} / \mathrm{L}$, which statistically credibly - by $12.87 \mathrm{mOsm} / \mathrm{L}$ differed from the average value of $299.78 \mathrm{mOsm} / \mathrm{L}$ in the control group (Mann-Whitney test, $\mathrm{p}<0.001$ ) (Figure 2.1). One month after the cataract surgery, compared to parameters registered one week after the surgery, the trend of reduction in osmolarity of eye tear film by $14.77 \mathrm{mOsm} / \mathrm{L}$ was observed in the study group, as a result of which the osmolarity tended towards returning to pre-surgery levels $-298.93 \mathrm{mOsm} / \mathrm{L}$, while no significant change was observed in the control group $-297.87 \mathrm{mOsm} / \mathrm{L}$. One month after the surgery, the difference in average values between the groups was not statistically significant $-1.07 \mathrm{mOsm} / \mathrm{L}$ (Mann-Whitney test, $\mathrm{p}<0.66$ ) (Figure 2.1).

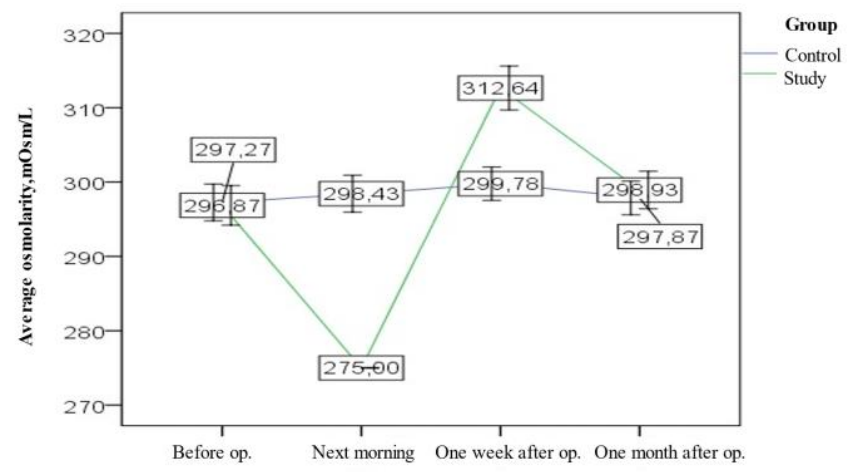

Figure 2.2 Average changes in eye tear film osmolarity in control and investigation groups over time 
As Figure 2.2 demonstrates, there was practically no dynamic change of osmolarity in the control group. This is further confirmed by repeated dispersion covariance analysis with the age of patient as a covariate $(\mathrm{p}=0.86)$. At the same time, statistically significant dynamic changes were observed in the investigation group $(\mathrm{p}<0.001)$, which, given the observed statistical power of 0.76 , provided certainty regarding the correctness of calculations. The calculated statistical effect is also high $\left(\eta^{2}=0.41\right)$. The obtained results confirm both work hypotheses that were set.

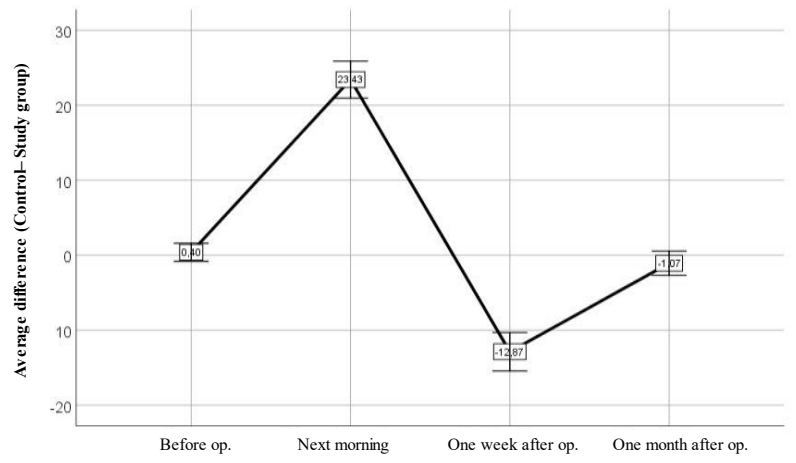

Figure 2.3 Average changes in the difference of eye tear film osmolarity in control/study groups over time

Repeated measurement covariance analysis showed that average changes in control/study group osmolarity difference over time are statistically significant $(\mathrm{p}<0.001)$ and patient age is not a statistically significant factor that affects change ( $p=0.21$ ). It can be observed (Figure 2.3 ) that no osmolarity changes between the control and study group exist before the surgery, but, on the morning that follows the surgery, a statistically credible decrease by an average of $23.03 \mathrm{mOsm} / \mathrm{L}$ (Post-hoc Bonferoni correction, $\mathrm{p}<0.001$ ), meanwhile one week after surgery, a statistically credible increase by an average of $36.3 \mathrm{mOsm} / \mathrm{L}$ is detected in comparison with the situation in the morning that follows surgery (Post-hoc Bonferoni correction, $\mathrm{p}<0.01$ ). Similarly, one month after 
the surgery, a statistically credible change in osmolarity is observed on average by $11.07 \mathrm{mOsm} / \mathrm{L}$ (Post-hoc Bonferoni correction, $\mathrm{p}=0.04$ ) (Figure 2.4).

\subsection{Classification of osmolarity results by degree}

Table 2.2

\section{Classification of control and study group patient osmolarity test results in dynamic change}

\begin{tabular}{|c|c|c|c|c|c|}
\hline & $\begin{array}{l}\text { Control } \\
\text { group }\end{array}$ & Study group & $\begin{array}{c}\mathbf{p} \\
\text { value }\end{array}$ & hi & $\begin{array}{c}\text { OR } \\
(95 \% \text { TI })\end{array}$ \\
\hline \multicolumn{6}{|l|}{ Before surgery } \\
\hline $\begin{array}{l}\text { Norm N (\%) } \\
\text { Hyperosmolarity } \\
\mathrm{N}(\%)\end{array}$ & $\begin{array}{l}57(63.33 \%) \\
33(36.67 \%)\end{array}$ & $\begin{array}{l}57(63.33 \%) \\
33(36.67 \%)\end{array}$ & - & - & - \\
\hline \multicolumn{6}{|c|}{ Next morning after surgery } \\
\hline $\begin{array}{l}\text { Hypo-osmolarity } \\
\mathrm{N}(\%) \\
\text { Norm N }(\%) \\
\text { Hyperosmolarity } \\
\mathrm{N}(\%)\end{array}$ & $\begin{array}{l}- \\
56(62.2 \%) \\
34(37.8 \%)\end{array}$ & $\begin{array}{l}90(100 \%) \\
- \\
-\end{array}$ & - & - & - \\
\hline \multicolumn{6}{|c|}{ A week after the surgery } \\
\hline $\begin{array}{l}\text { Norm N (\%) } \\
\text { Hyperosmolarity } \\
\mathrm{N}(\%)\end{array}$ & $\begin{array}{l}49(54.4 \%) \\
41(45.6 \%) \\
\end{array}$ & $\begin{array}{l}18(20 \%) \\
72(80 \%) \\
\end{array}$ & $\begin{array}{l}<0.0 \\
01\end{array}$ & 0.36 & $4.78(2.46-9.27 \%)$ \\
\hline \multicolumn{6}{|c|}{ A month after the surgery } \\
\hline $\begin{array}{l}\text { Norm N (\%) } \\
\text { Hyperosmolarity } \\
\mathrm{N}(\%)\end{array}$ & $\begin{array}{l}54(60 \%) \\
36(40 \%)\end{array}$ & $\begin{array}{l}53(58.9 \%) \\
37(41.1 \%)\end{array}$ & 0.50 & 0.01 & $1.04(0.57-1.89 \%)$ \\
\hline
\end{tabular}

* $<275 \mathrm{mOsm} / \mathrm{L}$ hypo-osmolarity of tear film; $275-300 \mathrm{mOsm} / \mathrm{L}$ physiological osmolarity of tear film; > $300 \mathrm{mOsm} / \mathrm{L}$ hyperosmolarity of tear film with loss of ocular surface homeostasis.

The classification of osmolarity dynamic change was developed on the basis of TearLab classification (Piera Versura \& Campos, 2013) (tearlab.com). Table 2.2 shows that, prior to surgery, the number of eyes with measurements within the limits of normal ranges is identical - like the number of eyes with hyperosmolarity observed prior to the surgery. The morning that followed the surgery was the only time when hypo-osmolarity was detected in all eyes 
included in the study group by the metering device, however, no such change was detected in the control group. The balance of unoperated eyes included in the control group did not change significantly between the normal limits and hyperosmolarity. Only a week after the surgery, the number of hyperosmolar eyes increased by 8 in comparison with the results obtained before surgery. Meanwhile, the osmolarity in the study group, where operated eyes of the patients were included, increased from hypo-osmolar in all eyes on the first day after the surgery to hyperosmolar in 72 eyes $(80 \%)$ one week after the performance of the cataract surgery, while in 18 patients (20\%), the osmolarity returned to normal limits. One month after the surgery $53(58.9 \%)$ of the eyes included in the study group had osmolarity within normal limits; furthermore, the statistical difference between the control and study group reduced.

As Table 2.2 shows, one week after the surgery, the difference between osmolarity change in control and study group is statistically significant $(\mathrm{p}<0.001)$ with medium statistical effect size $(\mathrm{Phi}=0.36)$. No such statistically

significant difference in the change of osmolarity between the control and investigation group was detected one month after the surgery $(\mathrm{p}=0.50)$.

Table 2.3

Osmolarity degrees of control and study groups

\begin{tabular}{|l|l|l|l|l|}
\cline { 2 - 5 } \multicolumn{1}{l|}{ Control group } & \multicolumn{1}{c|}{ Study group } & p value & $\boldsymbol{\varphi}$ \\
\hline $\begin{array}{l}\text { Before surgery } \\
\text { Norm N (\%) } \\
\text { Mild hyperosmolarity } \\
\text { N (\%) }\end{array}$ & $57(63.33 \%)$ & $57(63.33 \%)$ & 0.93 & 0.004 \\
$\begin{array}{l}\text { Moderate } \\
\text { hyperosmolarity N (\%) } \\
\text { Severe hyperosmolarity } \\
\text { N (\%) }\end{array}$ & $5(5.56 \%)$ & $29(32.22 \%)$ & & \\
- & $4(4.44 \%)$ & & \\
\hline
\end{tabular}


Table 2.3 continued

\begin{tabular}{|c|c|c|c|c|}
\hline & Control group & Study group & p value & $\varphi$ \\
\hline \multicolumn{5}{|c|}{ Next morning after surgery } \\
\hline Hypo-osmolarity $\mathrm{N}(\%)$ & - & $90(100 \%)$ & - & - \\
\hline Norm N (\%) & $56(62.22 \%)$ & - & & \\
\hline Mild hyperosmolarity & & & & \\
\hline $\mathrm{N}(\%)$ & $31(34.44 \%)$ & - & & \\
\hline Moderate & & & & \\
\hline hyperosmolarity N (\%) & $2(2.22 \%)$ & - & & \\
\hline Severe hyperosmolarity & & & & \\
\hline $\mathrm{N}(\%)$ & $1(1.11 \%)$ & - & & \\
\hline \multicolumn{5}{|l|}{ A week after surgery } \\
\hline Norm N (\%) & $49(54.44 \%)$ & & $<0.001$ & 0.31 \\
\hline $\mathrm{N}(\%)$ & $38(42.22 \%)$ & $48(53.33 \%)$ & & \\
\hline $\begin{array}{l}\text { Moderate } \\
\text { hyperosmolarity N (\%) }\end{array}$ & $3(3.33 \%)$ & $19(21.11 \%)$ & & \\
\hline Severe hyperosmolarity & & & & \\
\hline $\mathrm{N}(\%)$ & - & $5(5.56 \%)$ & & \\
\hline \multicolumn{5}{|l|}{ A month after surgery } \\
\hline Norm N (\%) & $54(60 \%)$ & $53(58.89 \%)$ & 0.92 & 0.002 \\
\hline $\begin{array}{l}\text { Mild hyperosmolarity } \\
\mathrm{N}(\%)\end{array}$ & $33(36.67 \%)$ & $33(36.67 \%)$ & & \\
\hline Moderate & & & & \\
\hline hyperosmolarity N (\%) & $3(3.33 \%)$ & $4(4.44 \%)$ & & \\
\hline $\begin{array}{l}\text { Severe hyperosmolarity } \\
\mathrm{N}(\%)\end{array}$ & - & - & & \\
\hline
\end{tabular}

* $<275 \mathrm{mOsm} / \mathrm{L}$ hypo-osmolarity of tear film; $275-300 \mathrm{mOsm} / \mathrm{L}$ physiological osmolarity of tear film; $300-320 \mathrm{mOsm} / \mathrm{L}$ hyperosmolarity with mild loss of ocular surface homeostasis; 320 - $340 \mathrm{mOsm} / \mathrm{L}$ hyperosmolarity with medium severity of the loss of ocular surface homeostasis; > $340 \mathrm{mOsm} / \mathrm{L}$ hyperosmolarity with severe loss of ocular surface homeostasis (Piera Versura \& Campos, 2013) (tearlab.com).

Upon the evaluation of osmolarity degree in control and study groups (See Table 2.3), the conclusion was made that the division of osmolarity into degrees does not differ statistically significantly for control and investigation group $(p=0.93)$ with unremarkable statistical effect size. Statistically significant $(p<0.001)$ changes in the distribution of osmolarity for the control and investigation group are observed one week after the surgery with medium statistical effect size $(\mathrm{Phi}=0.31)$. No statistically significant difference 
in osmolarity degree between the control and investigation group was detected one month after surgery $(\mathrm{p}=0.92)$.

\subsection{Osmolarity one month after surgery}

As demonstrated in Figure 2.4 A), 51 (56.67\%) of control group patients retained tear osmolarity within the normal range one month after surgery, while $6(6.67 \%)$ of the patients with normal measurements before surgery had hyperosmolarity one month after surgery. Among the control group patients with increased osmolarity before surgery, $3(3.33 \%)$ patients had their osmolarity stabilised within the normal limits one month after the surgery, while in $30(33.33 \%)$ patients hyperosmolarity persisted. Calculation of the total change before surgery and one month after the surgery, no statistically credible changes could be detected in the control group (McNemar's test, $\mathrm{p}=0.50$ ). In the investigation group (Figure $2.4 \mathrm{~B})$ ), like in the control group, 51 (56.67\%) patients retained tear osmolarity within the normal range one month after surgery, while $6(6.67 \%)$ of the patients with normal measurements before surgery had hyperosmolarity. Out of all 33 eyes with hyperosmolarity before surgery in the study group, $2(2.22 \%)$ patients had normal osmolarity after a month and 31 (34.44\%) patients retained hyperosmolarity. Calculation of total changes before the surgery and one month after the surgery allows one to conclude that no statistically significant changes are detected (McNemar's test, $\mathrm{p}=0.51)$. 

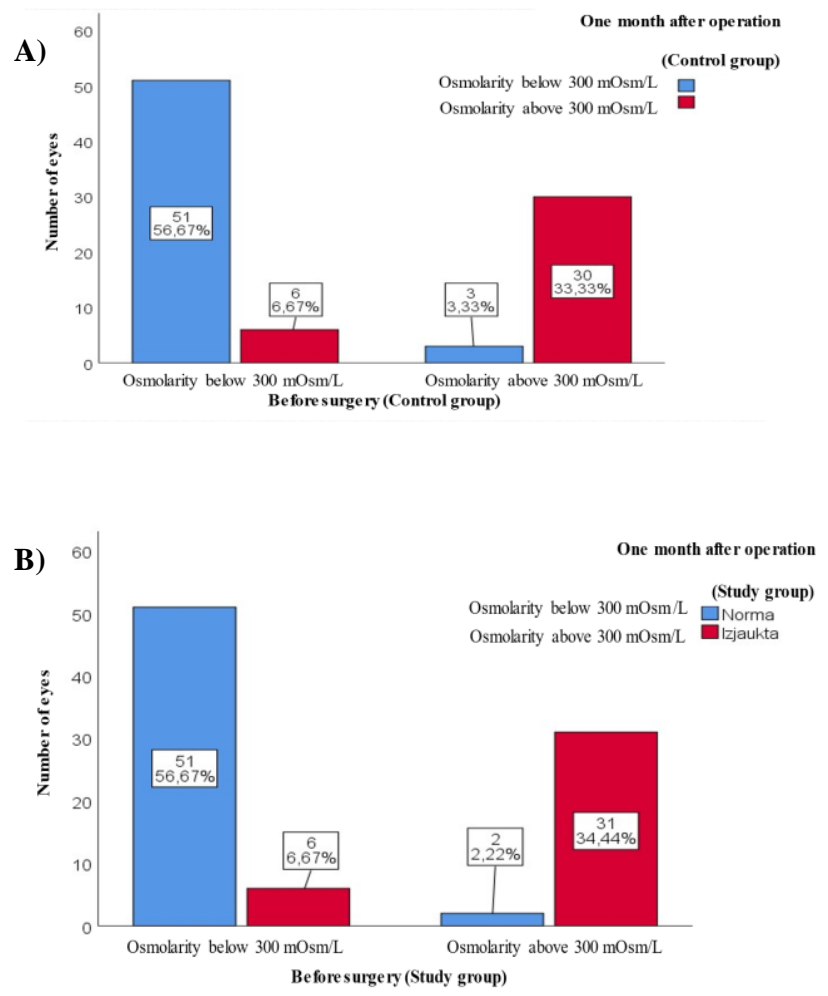

Figure 2.4 Changes in osmolarity norm one month after cataract surgery A) in control, B) in study group

Upon the analysis of the total dynamic change of osmolarity in both eyes (Figures 2.5 and 2.6), the conclusion was made that 50 (55.56\%) patients had normal osmolarity in both eyes before the surgery. One week after the surgery, $14(15.55 \%)$ patients retained normal osmolarity. Data calculations one month after surgery indicate that $43(48.89 \%)$ patients retained normal eye osmolarity within the range from 275 to $300 \mathrm{mOsm} / \mathrm{L}$ (Figure 2.8). One month after surgery, tear osmolarity in $7(7.78 \%)$ patients, at least in one eye, became hyperosmolar (Figure 2.6). Prior to the surgery, in $40(44.44 \%)$ patients a hyperosmolar 
measurement was registered in at least one of the eyes, while, one month later, $39(43.33 \%)$ patients retained hyperosmolarity in one or both of the eyes. Normalisation of osmolarity in both eyes was only registered for $1(1.11 \%)$ patient (Figure 2.9). In McNemar's test analysis, the norm of both eye osmolarity did not demonstrate a statistically significant change $(\mathrm{p}=0.07)$.

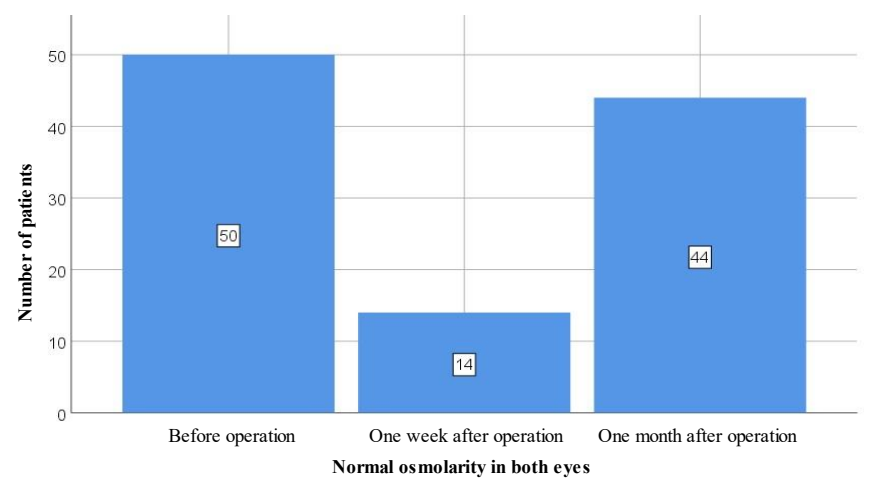

Figure 2.5 Dynamic change of the number of patients with normal osmolarity registered in both eyes over time

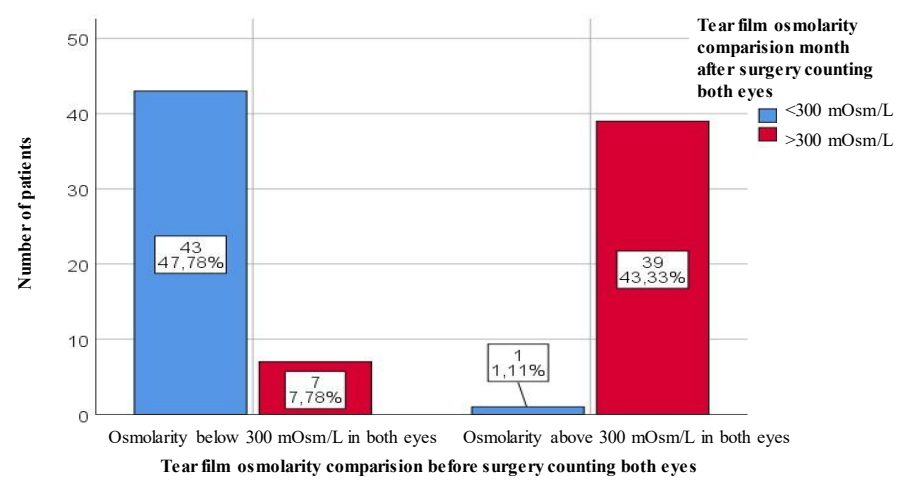

Figure 2.6 Changes in the number of patients, with registered normal osmolarity in both eyes one month after surgery, in comparison with initial data before surgery 


\subsection{Difference in osmolarity between eyes as an indicator of loss of homeostasis}

The guidelines of TearLab emphasise that the differences in tear film osmolarity that exceeds $8 \mathrm{mOsm} / \mathrm{L}$, which points to the loss of ocular surface homeostasis in the eye that has demonstrated the highest measurement (Piera Versura \& Campos, 2013). When analysing data according to this criterion, it was found that the difference of tear film osmolarity between two eyes of $14(15.56 \%)$ patients had been larger than $8 \mathrm{mOsm} / \mathrm{L}$ before the surgery. The measurements in the morning after the surgery were not compared according to this criterion, considering the fact that the obtained results were hypo-osmolar beyond the detection range of the device and the obtaining of precise numerical value was impossible. One week after the surgery, osmolarity between two eyes differed by more than $8 \mathrm{mOsm} / \mathrm{L}$ in $63(70 \%)$ patients, while, after a month, the number of patients with the loss of ocular surface homeostasis reduced to $28(31.11 \%)$ (Figure 2.7$)$.

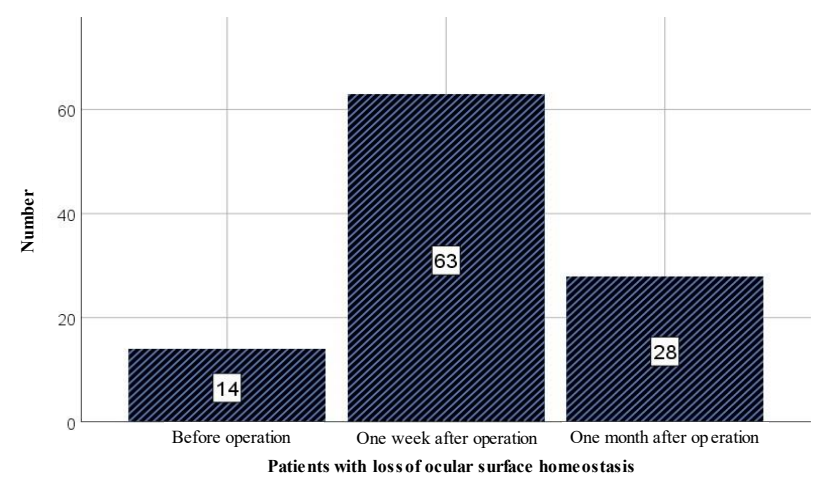

Figure 2.7 Dynamic change in the number of patients with the loss of ocular surface homeostasis 
Before surgery the difference of osmolarity between both eyes did not exceed $8 \mathrm{mOsm} / \mathrm{L}$ in $76(84.44 \%)$ patients. The analysis of changes of homeostasis before surgery and one month after surgery (Figure 2.11) allows one to conclude that the difference of osmolarity between both eyes below $8 \mathrm{mOsm} / \mathrm{L}$ was retained in $52(57.78 \%)$ patients one month after surgery, while the difference of osmolarity exceeded $8 \mathrm{mOsm} / \mathrm{L}$ in 24 (26.67\%) patients, who initially had the difference of osmolarity below $8 \mathrm{mOsm} / \mathrm{L}$. Before the surgery the difference of osmolarity between both eyes exceeded $8 \mathrm{mOsm} / \mathrm{L}$ in $14(15.56 \%)$ patients. Out of these patients, the reduction in the difference between eye osmolarity below $8 \mathrm{mOsm} / \mathrm{L}$ occurred in $10(11.11 \%)$ patients, while $4(4.44 \%)$ patients retained the osmolarity difference of more than $8 \mathrm{mOsm} / \mathrm{L}$. Upon the evaluation of the changes in homeostasis and on the basis of the difference between both eyes, the author of the Thesis has concluded that statistically significant changes remain one month after cataract surgery $(\mathrm{p}=0.02)$.

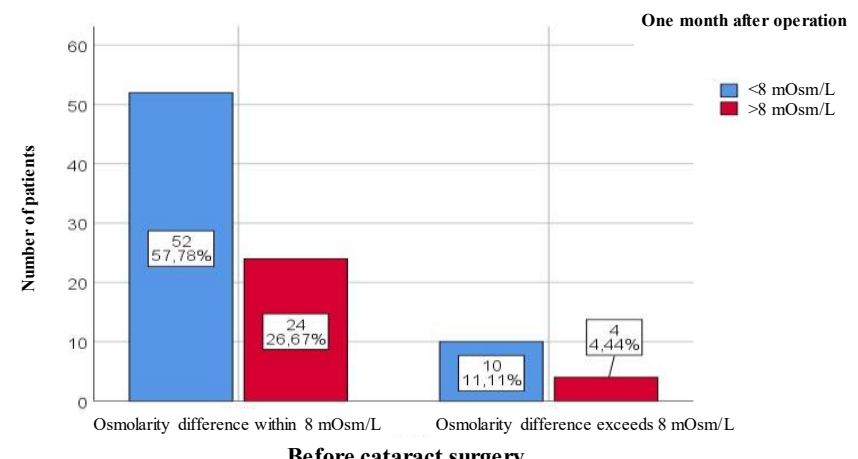

Figure 2.8 The numerical changes in homeostasis one month after the surgery, compared to the data before the surgery 


\subsection{Association of osmolarity with patients' gender and age}

Evaluation of average osmolarity changes in men and women separately, including the data on the differences between the control and study group in dynamic change, failed to provide data regarding statistically significant differences $(p>0.05)$ (See Figure 2.9).

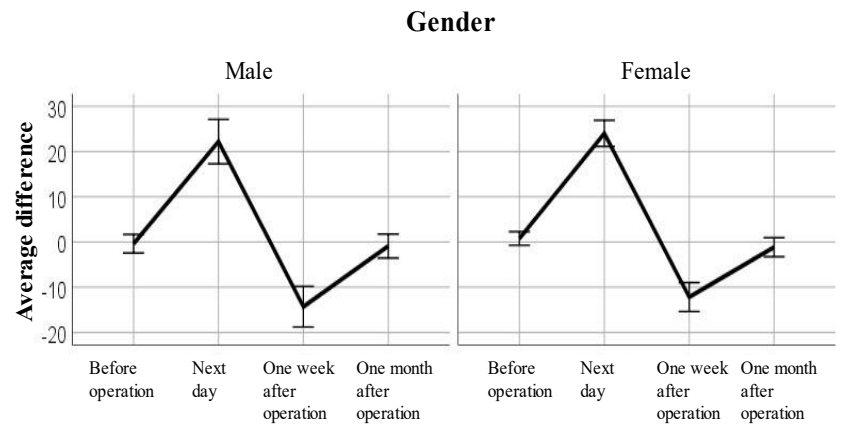

Figure 2.9 Changes in osmolarity depending on the patients' gender

As Figure 2.10 demonstrates, a positive, weak, and statistically significant association is detected between the age of patients and the difference in osmolarity one month after the surgery $(r=0.18 ; 95 \%$ TI: $0.02-0.37 ; \mathrm{p}=0.03)$. The linear regression analysis allows one to conclude that, with every year of life of a patient, the difference in osmolarity before the surgery and one month after the surgery increases on average by 0.30 (95\% TI: $0.0-0.63) \mathrm{mOsm} / \mathrm{L}$. Multifactor regression analysis failed to provide statistically credible data regarding the effect of gender on the difference in osmolarity before the surgery and one month after the surgery $(\mathrm{p}>0.05)$. 


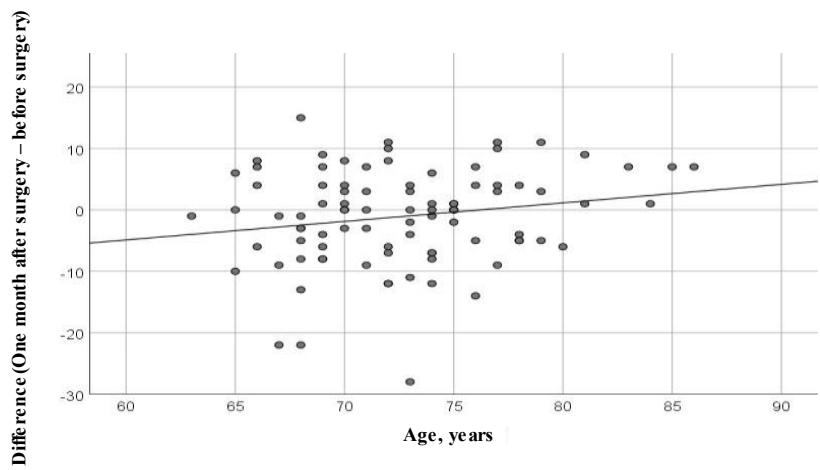

Figure 2.10 The correlation diagram between patients' age and difference in osmolarity before the surgery and one month after the surgery in study group 


\section{Discussion}

The osmolarity of eye tear film has been researched earlier and several evidence-based sources of literature on this topic are available (Khanal \& Millar, 2012). It could be considered that the decision to monitor patients for one month after surgery was substantiated by the fact that other research has already proven that the osmolarity one month after surgery does not statistically credibly differ from the parameters before surgery. Personal observations were also important - patients have pronounced complaints characteristic of ocular surface disease during the first weeks after cataract surgery, for instance, discomfort of ocular surface, grinding, burning, itching sensations, lacrimation, feeling of a foreign body, which, based on literature data, confirmed the aggravation of a pre-existing DES or activation of asymptomatic DES (Adeeb M Rushdi, 2018) (Gupta et al., 2018).

In October 2016, an article on the prospective cohort study conducted at one of the university hospitals of Spain was published in the American Journal of Ophthalmology. The study analysed the changes in tear osmolarity and relation thereof with the ocular surface disease index (OSDI) in patients after the cataract surgery. OSDI is a questionnaire containing 12 questions that helps the physician to assess the degree of severity of an ocular surface disease. 52 patients with unilateral cataract, who have been referred for a scheduled surgery, were included in the study. The eye that was subject to surgery was included in the investigation group, the healthy eye was included in the control group. Patients, who were regular users of glaucoma medications, or patients with a history of eye surgery were not included in the study. Assessment of tear osmolarity and OSDI was performed before the surgery, one month and three months after the surgery. Interpretation of results lead to observation that tear osmolarity does not demonstrate statistically significant change in the investigation group: $305.63 \pm 15.07 \mathrm{mOsm} / \mathrm{L}$ before surgery, $305.70 \pm 16.48 \mathrm{mOsm} / \mathrm{L}$ one month 
after surgery, $303.88 \pm 11.75 \mathrm{mOsm} / \mathrm{L}$ three months after the surgery $(\mathrm{p}=0.067)$, as well as in the control group: $309.74 \pm 15.92 \mathrm{mOsm} / \mathrm{L}$ before, $306.74 \pm 13.22 \mathrm{mOsm} / \mathrm{L}$ one month after and $303.19 \pm 11.02 \mathrm{mOsm} / \mathrm{L}$ three months after the surgery $(\mathrm{p}=0.064)$. The measurements did not differ statistically significantly between the groups (Gonzalez-Mesa et al., 2016). Considering the data obtained at university hospitals of Spain, which did not demonstrate a statistically significant change, the decision was made to pay closer attention to the study and analysis of the first month after the surgery. It must be added that the trend of osmolarity figures to return to pre-surgery levels was observed in the data obtained during this study as well. Upon a more detailed review of OSDI questionnaire results, it can be seen that patients were included in groups on the basis of osmolarity figures before surgeries. Patients with tear osmolarity that exceeded $312 \mathrm{mOsm} / \mathrm{L}$ were included in the hyperosmolar group, while the control group consisted of patients with osmolarity below $312 \mathrm{mOsm} / \mathrm{L}$ before the surgery. Ocular surface disease index between the two groups differed statistically significantly $(\mathrm{p}=0.01)$ before surgery and three months after surgery $(\mathrm{p}=0.01)$, meanwhile no difference between results was observed one month after the surgery $(p=0.7)$. The conclusions of the study recognised that patients with tear osmolarity that exceeds $312 \mathrm{mOsm} / \mathrm{L}$ before surgery will experience discomfort in the operated eye after the surgery (Gonzalez-Mesa et al., 2016). The results reflected in the study coincide with the information included in the literature description of the Thesis, which reminds one of the aggravation of DES symptoms after the surgery in patients with hyperosmolarity or activation of asymptomatic DES (Adeeb M Rushdi, 2018). The aforementioned study is only one of several studies that urges specialist ophthalmologists to consider the introduction of the tear osmometry test before the cataract surgery as a routine investigation to detect risk group patients and avoid undesirable post-surgical complications. 
Currently, ophthalmology uses the osmolarity of the tear film as a diagnostic marker to diagnose DES, determine the severity degree thereof and monitor the efficiency of DES therapy (Lemp et al., 2011) (Sullivan et al., 2010). A study is available in the literature dedicated to the topic, which included 163 articles that have studied the correlation between DES symptoms and changes in tear osmolarity. In $72 \%$ or 117 of 163 articles, the tear osmolarity test is recognised as a useful and important marker for DES diagnostics, as well as for the assessment of its degree of severity and efficiency of therapy. A strong and statistically significant correlation between the increase in osmolarity and the aggravation of DES clinical symptoms was observed in the studies (Potvin et al., 2015). It must be additionally mentioned that osmolarity is the only ocular surface marker that can reflect the degree of DES severity on the basis of the obtained numerical value (Narayanan, 2011).

Previously proven statistically significant correlation between DES symptoms and the increase in osmolarity was one of the most important criteria for the exclusion of subjective symptoms of patients from this study. The description of literature mentions that symptoms of DES patients may vary a lot and be radically different (Adeeb M Rushdi, 2018). The same applies to the clinical finding that is rather variable, because DES may occur without a structural clinical finding, namely, no signs of irritation of the ocular surface will be detected (Narayanan, 2011). The aforementioned specific characteristics served as the reason not to include symptoms and clinical findings for further research in the dissertation in order to avoid additional interfering factors.

To make the research unique and results thereof binding, patients with an intact ocular surface were included as much as possible, as well as strict exclusion criteria were developed. One of the criteria was the exclusion of lens users from the study, because, on the basis of literature data, the opinions of ophthalmologists on the issue differ worldwide. Some specialists believe that 
the regular use of contact lenses increases the osmolarity of tears (Nichols \& Sinnott, 2006) (Miller et al., 2004) (Muselier-Mathieu et al., 2014), while others believe that the osmolarity of tears is not changed (DEWS, 2007) (Chen et al., 2013). The contrasting data that is observed in the reported research results can be explained by the ability of contact lens users to retain homeostasis of the ocular surface by preventing the drying effect caused by an ocular surfacefriendly, but, still, a foreign body - contact lens (Nichols \& Sinnott, 2006). Upon the review of the exclusion criteria, it can be seen that patients that have been diagnosed with diabetes mellitus were not included in the study. It has been proven that diabetes mellitus patients have increased osmolarity of the eye tear film (Alves et al., 2014) (Sagdik et al., 2013). Various ophthalmological pathologies alter the homeostasis of the ocular surface. For instance, pseudoexfoliation syndrome, which is rather common in the Scandinavian population (Astrom \& Linden, 2007), changes the activity of conjunctival goblet cells and the production of mucin, which forms the internal base layer of the tear film (Kozobolis et al., 2004) (Erdogan et al., 2006). As a result, patients with pseudoexfoliation syndrome are characterised by increased osmolarity of the eye tear film (B. A. Oncel et al., 2012). Another example is surfer's eye (Latin-pterygium) - which is characterised by growth of the conjunctival mucous membrane in the direction towards the centre of the cornea due to the inflammatory process (Malozhen et al., 2017). The patients with pterygium also have increased osmolarity of the tear film of the eye, which results from chronic irritation of the ocular surface and the reduction of goblet cell count (Julio et al., 2012). Finally, the use of eye drops has been proven to have various effects on tear film osmolarity. Eye drops for glaucoma that the patients must use at least once per day and that contain preservatives like benzalkonium chloride, create inflammatory changes in the ocular surface. This results in dry eye syndrome with considerably increased tear film osmolarity. A positive aspect is the fact that 
glaucoma medications have no proven negative effect on other ocular surface examinations, for instance, Schirmer's test and tear film stability tests (Tear film break up time) (S.-Y. Lee et al., 2013) (Tomlinson et al., 2013) (Labbe et al., 2012). At the same time, most clinical studies have proven that artificial tears, which are prescribed as the medication of first choice for the treatment of the dry eye syndrome, reduce the osmolarity of the tea film (J.-E. Lee et al., 2014) (Iester et al., 2000). Despite this statement, a separate study failed to detect the association between osmolarity and the use of artificial tears. In the study this is associated with the molecular composition of a particular medication (Comez et al., 2013). It is believed that the use of low osmolarity artificial tears reduce the osmolarity of the tear film of the ocular surface (Montani, 2013). The effect of anti-inflammatory eye drops on the homeostasis of the ocular surface is the least clear issue. The options of research are limited, considering the severe structural changes of the eyeball caused by the underlying disease. Due to this reason, there is no common opinion on osmolarity changes in the event of topical use of anti-inflammatory medications (Bunya et al., 2013) (Di Tommaso et al., 2012) (Sullivan et al., 2012). It must be emphasised that anti-inflammatory drugs (glucocorticosteroids), as well as cytostatics are indicated in the cases of severe dry eye syndrome (Zhang et al., 2017).

Considering the effect of the factors listed above on the homeostasis of the ocular surface, as well as to create a patient group with as intact an ocular surface as possible and to assess the changes of tear film at early stages after the cataract surgery, the appropriate inclusion and exclusion criteria were developed to prevent the selection of patients with previously described ophthalmological conditions in the study.

When returning to the effect of eye drops on osmolarity, which has been earlier confirmed to be a factor that changes the homeostasis of the ocular surface, the considerable lack of research must be mentioned, which prevents 
the ability to claim that the cataract surgery has an undeniable effect on the changes in measurements registered in the study(Sutu et al., 2016). After the surgery, patients are routinely prescribed antibiotic and anti-inflammatory drops in the operated eye. The intensity of administration of the drops is reduced every week over a period of one month, which coincides with the time period, when osmolarity measurements, in accordance with the results obtained in the study, return to pre-surgery levels. It must be noted that drops were not used in the control group or the eye, where the cataract surgery was not performed. It would be dangerous not to use anti-inflammatory and antibacterial drops after the surgery, furthermore - it would be contrary to the guidelines(ESCRS, 2007), therefore one of the options for further research aimed at investigating the effect of cataract on the changes in ocular surface osmolarity in more detail would involve the use of the same post-surgical drops in the eyes of control group in accordance with the scheme that is identical to the one used in the operated eye. Considering the above information, it cannot be claimed that a cataract surgery is the only factor that undeniably changes tear osmolarity during the first post-surgical month.

The design of the study was developed to include patients with the healthiest ocular surface possible. During the development of the study design, it was not forecast that a considerable number of patients will present with hyperosmolarity before the surgery. Before the surgery increased osmolarity in both the operated eye and the eye that was not affected by surgery was detected in 33 patients (36.67\%) (See Table 2.3) and the highest measurement reached $337 \mathrm{mOsm} / \mathrm{L}$ (See Table 2.1), which complies with medium-severe loss of ocular surface homeostasis (Piera Versura \& Campos, 2013). It was already mentioned in the literature description that DES is defined as instability of the tear film with increased osmolarity (DEWS, 2007) (Craig et al., 2017). This is even more interesting due to the fact that only patients, who did not mark any symptoms 
of ocular surface discomfort in the DES symptom questionnaire, were included into the study. The results again confirm that specialists in ophthalmology, including cataract surgeons, are not aware of the actual incidence of DES among cataract patients. On the basis of the obtained osmolarity data, asymptomatic DES was detected in 33 patients, who did not report any symptoms of DES before the surgery, which, according to the information summarised in the literature, has the tendency to aggravate after the surgery (Narayanan, 2011) (Adeeb M Rushdi, 2018). The aforementioned information again proves that ocular surface with disrupted homeostasis is a challenge for practical ophthalmology. The osmometry data obtained before the surgery create the outlook on the clinical variety of DES and the actual prevalence thereof among patients. The design of the Thesis and the results thereof demonstrate that tear film osmometry is an important patient screening method to be performed before surgery.

When taking a detailed look at the results of the research, it can be seen that the average eye osmolarity parameters between eyes differ by tenths and fall within the normal range of below $300 \mathrm{mOsm} / \mathrm{L}$, i.e. conform to ocular surface with undisrupted homeostasis (Lemp et al., 2011). In contrast, in the morning that followed the surgery or on the first day after surgery, a statistically significant reduction in the osmolarity of tear film was observed in the investigation group, namely, the tears in the operated eye became hypo-osmolar. The tear film of the eyes not only became hypo-osmolar, it reduced so significantly that it could not be determined exactly by using the TearLab metering device - osmolarity in the morning that followed the cataract surgery was beyond the detection range of the metering device $(275-400 \mathrm{mOsm} / \mathrm{L})$. A noteworthy fact - such measurement was detected in all patients included in the study in the morning that followed the cataract surgery. The pronounced reduction of osmolarity could be explained by severe irritation of the ocular 
surface after the manipulation, which induces hyperfunction of the tear gland and increased lacrimation (Sutu et al., 2016). Although, during incisions made in the cornea and use of the ultrasound energy after the extraction of the lens, the nerve endings of the cornea are damaged (Kohli et al., 2019), as a result of which, the feedback mechanism is disrupted, which stimulates the lacrimal gland (Chuang et al., 2017). Furthermore, the fact that antibiotic and anti-inflammatory eye drops are intensively used during the first days after the cataract surgery must not be forgotten(Zhang et al., 2017). It must be noted that their effect on the homeostasis of the ocular surface is not as pronounced as that of the surgery(Sutu et al., 2016). The use of post-surgical drops and the disruption of the feedback mechanism is resulting in the insufficient production of tears and changes in tear composition (Chuang et al., 2017). Thus, on the first day after surgery, the composition of tears is significantly diluted. In the control group, where the osmolarity of the tear film did not demonstrate a statistically significant change in the morning after the surgery, a mutual comparison between groups demonstrated a statistically significant difference.

The increase in osmolarity of the tear film was observed one week after the surgery, which considerably exceeded the normal ranges of the healthy eye and statistically significantly differed from the control group. During the analysis of results one week after the surgery, it must be considered that any surgery, including minimally invasive surgery, is traumatic for human tissue. It is proven that, after cataract surgery, the number of mucin layer producing goblet cells in the conjunctiva statistically significantly reduces. This directly affects the quality of tears and is considered to be one of the main pathological DES causing factors after the surgery (Oh et al., 2012). In addition to the reduction of conjunctival goblet cells, the traumatic injury of corneal epithelium caused by manipulations performed during the cataract surgery must also be taken into consideration (Cha et al., 2004) (Adeeb M Rushdi, 2018). Delayed healing of epithelial scars, 
increased epithelial permeability, reduced metabolic activity of the epithelium and loss of cytoskeleton structures are observed after the surgery (Lum et al., 2019). Clinically, inflammation of the cornea is observed with a reduction in sensitivity and tear secretion (X. Liu et al., 2008). Apart from structural tissue damage caused by the surgery, it must be remembered that post-surgical drops contain preservatives that, if used alone, can cause inflammatory reaction (Sutu et al., 2016). As concluded by this study, there are grounds to believe that all of the aforementioned factors serve as the cause for the altered homeostasis of the ocular surface and increased osmolarity. Another noteworthy fact is that one week after surgery is the period, when the highest concentration of inflammation factors is observed in the human body - it is this time when the highest tear film osmolarity results were observed in the investigation group (Sutu et al., 2016).

A trend of equalisation of the average results was observed one month after surgery, namely, the osmolarity of the tear film in the investigation group returned to pre-surgical levels, as well as the results between the investigation group and the control group did not statistically significantly differ. Thus, a conclusion can be made that the homeostasis of ocular surface is restored approximately one month after cataract surgery. It is impossible to determine the precise time, however, as this study had several limiting factors. For instance, one of them is the frequency of post-surgical patient visits, which amounted to three visits during the post-surgery period. Despite this, the author of the work believes that it is possible to claim that one month is a sufficient time period to restore the healthy surface of the eye.

Despite the fact that average tear osmolarity parameters between groups equalised, hyperosmolarity among patients was still registered in patients one month after surgery. Actually, the number of patients with hyperosmolar tear film one month after surgery remained comparatively high. In the investigation group, osmolarity of more than $300 \mathrm{mOsm} / \mathrm{L}$ was detected in 37 eyes $(41.1 \%)$, 
while in the control group it was detected in 36 eyes (40\%) (See Table 2.2). Before the surgery the measurements of 33 eyes (36.67\%) exceeded the mark of $300 \mathrm{mOsm} / \mathrm{L}$, which is a slightly lower figure in comparison with measurements made after the surgery, however, it does not constitute a statistically significant difference. Upon the review of Figure 2.7, which demonstrates a more detailed categorisation and provides osmometry output data before surgery, it can be seen that out of 57 eyes in the control group that demonstrated the result of 275-300 mOsm/L, $6(6.67 \%)$ eyes retained hyperosmolarity one month after the surgery. Meanwhile, out of 33 eyes that were hyperosmolar before the surgery, 3 eyes fell within the normal range of ocular surface osmolarity. No statistically significant difference was detected for the described changes (McNemar's test, $\mathrm{p}=0.50$ ). Similar data were obtained in the investigation group as well (Figure 2.7. B). Out of 57 eyes with normal osmolarity before the surgery, $6(6.67 \%)$ eyes remained hyperosmolar. Meanwhile $2(2.22 \%)$ eyes demonstrated a reduction in osmolarity below $300 \mathrm{mOsm} / \mathrm{L}$ in patients whose tears were hyperosmolar before the surgery. Like in the control group, the calculation of the total changes failed to detect a statistically significant change (McNemar's test, $\mathrm{p}=0.51$ ). The obtained osmometry measurements and analysis of dynamic changes thereof, as well as comparison between groups, allow one to conclude that one month is sufficient to return osmolarity parameters to levels detected before surgery and to restore the homeostasis of the ocular surface.

Another interesting conclusion that can be made on the basis of the results obtained in the study is the fact that, as a result of comparison of the difference in osmolarity measurements before and one month after the surgery, the difference in the investigation group increased by an average of $0.30 \mathrm{mOsm} / \mathrm{L}$ with every year of the patient's age (See Figure 2.13). The result of linear regression analysis can be explained by an association that has been previously proven, which states that the regeneration capacity of human body is slowing 
down with age (Nagelschmidt \& Engelhardt, 1983) (Eaglstein, 1989) (Jones \& Millman, 1990) (Gerstein et al., 1993). This newly discovered fact can serve as one of the promising directions of research that would enable more precise analysis of ocular surface recovery capacity and recovery rate depending on age.

Why is determining tear osmolarity required before the surgery? It is essential not only to avoid subjective symptoms of dry eye after surgery, but also to avoid refraction errors, when calculating the artificial intraocular lens and prescribing glasses for reading (Ito \& Shimizu, 2009). It has been proven that undiagnosed ocular surface disease with pronounced changes in tear osmolarity compromises visual acuity and may cause an insufficient refractive outcome after the cataract surgery, which will manifest in the patient as a constant blurring of vision and affect their further quality of life (Epitropoulos et al., 2015).

Based on literature data, the thickness of tear film varies from $6 \mu \mathrm{m}$ to 20 $\mu \mathrm{m}$ and the refractive power does not differ by more than $0.1 \mathrm{D}$ between instances of blinking. In the event of tear film instability, which occurs in the event of hyperosmolarity, the refractive power may change by more than $1 \mathrm{D}$ between blinking, which considerably affects the visual acuity of patients (Béatrice Cochener-Lamard, 2019).

The study "Effect of tear osmolarity on repeatability of keratometry for cataract surgery planning" used the same technical device (IOLMaster) to analyse deviations in keratometry data before the cataract surgery and intraocular lens calculations in patients with increased osmolarity in two different visits. The control group included patients with tear film osmolarity in both eyes that did not exceed $308 \mathrm{mOsm} / \mathrm{L}$, while in the investigation group the osmolarity of the tear film of the patients exceeded $316 \mathrm{mOsm} / \mathrm{L}$, consequently - hyperosmolar. Parameters like keratometry data, corneal astigmatism and strength of intraocular lens were analysed in two visits with a three-week interval. The dynamic change of results was compared in each group, as well as between groups. It is worth 
noting that in the hyperosmolarity group, the variability of keratometry results was statistically significantly higher during both visits in comparison with the control group $(\mathrm{p}=0.05)$, as well as the percentage of patients with a differing astigmatism calculation by 1.0 dioptre was statistically significantly higher after three weeks $(\mathrm{p}=0.02)$. Upon the evaluation of artificial intraocular lens calculation, the percentage of patients in the hyperosmolar group with the calculation result difference of $0.5 \mathrm{D}$ is statistically higher than in the control group. Considering the above, one of the conclusions of the study bears evidence that the determination of tear film osmolarity during the planning of cataract surgery is an efficient method for the identification of patients with a high risk of suffering from undesirable post-surgical refraction errors caused by imprecise keratometry calculations (Epitropoulos et al., 2015) (Trattler et al., 2017).

Another study researched the effect of artificial tears on keratometry measurements. It is worth noting that after the application of artificial tears in the investigated eye, the results of keratometry changed by more than $0.5 \mathrm{D}$ in $34 \%$ of the patients from DES group, whilst a similar change was only observed in $13 \%$ of patients with a healthy ocular surface. The conclusions of the study confirm the undeniable effect of DES syndrome on keratometry measurements, as well as recommend the use of artificial tears in risk group patients at least 5 minutes prior to the performance of keratometry to obtain as precise results of the IOL calculation as possible (Röggla et al., 2021).

As cataract surgery evolves, patient expectations are growing as regards the improvement of visual acuity and the opportunity of seeing without the need for eyeglass correction. Studies that have summarised the results of cataract surgeries have led to conclusions that in $50-70 \%$ of the patients the deviation from target refraction is up to $0.5 \mathrm{D}$; in $79-94 \%$ of the patients the deviation from the set target refraction is up to 1 D (Lagrasta et al., 2009) (Cooke \& Cooke, 2016) (Aristodemou et al., 2011a) (Aristodemou et al., 2011b) (E. Holland et al., 
2010). The degree of deviation from target refraction that will cause clinical symptoms in patients, depends to a high degree on the patients themselves. Refraction error after cataract surgery is mostly manifested as blurring of distance vision. The expectations of a patient from the surgery include good distance vision without correction, which, given refraction error as a postsurgical complication, is not reached. In literature refraction error is usually analysed based on the percentage of patients with target refraction falling within the limits of $0.5 \mathrm{D}$ and $1 \mathrm{D}$ after surgery. It has been convincingly proven that the deviation of more than $1 \mathrm{D}$ from target refraction will result in the clinically symptomatic blurring of vision in patients; meanwhile, if it is lower than one dioptre, blurring of vision may not be observed(Gale et al., 2009). The aforementioned deviation up to the interval of $0.5 \mathrm{D}$ is the highest practically possible precision in the event of the performance of cataract surgery with the implantation of IOL in the posterior capsule (E. S. Lee et al., 2005).

It must be added that the emphasis of this dissertation is on patients with a healthy ocular surface, however, despite that, mild or medium hyperosmolarity was detected in 33 eyes before the surgery (Table 2.3). The surprisingly high number of hyperosmolar eyes among patients included in the study allows one to realise the seriousness of the situation, since each of these 33 patients had an increased risk of having post-surgical refraction error. As the development of cataract surgery in Latvia continues, the research and diagnostics of ocular surface tear osmolarity plays an important role to take a look towards refractive surgery, where the principal expectation of the patient is to get rid of eyeglasses after surgery and even the tiniest calculation error or incorrect selection of the lens may cause lasting consequences and affect the quality of life of the patient. The data obtained during the development of the dissertation will enable specialists to obtain an in-depth understanding of the role of ocular surface 
condition in the calculations of IOL, as well as gain the awareness of the risks to consider in order to avoid post-surgical refractive errors.

Nowadays, when cataract surgery slowly, but inevitably develops in the direction of refractive surgery, the need for cataract and refractive surgeons to pay more attention to ocular surface condition before, as well as after the surgery is emphasised more frequently and persistently, since it enables one to avoid unexpected refraction errors and ensure that the outcome of surgical therapy improved quality of vision - would conform to patient expectations (He et al., 2017) (E. J. Holland et al., 2016). In the event of severe dry eye syndrome the surgery is postponed and the ocular surface is treated first to ensure that the changes caused by the disease leave the least possible effect on lens calculations and the outcome of the surgery (Epitropoulos et al., 2015).

The practical use and importance of this study must also be emphasised. A patient, who receives a monofocal lens implant during the cataract surgery, will require glasses for reading or, less frequently, for distance vision, if the patient opts in favour of good near vision (Ito \& Shimizu, 2009). These patients are recommended to purchase new glasses for reading no earlier than after one month following the surgery (Radner et al., 2014). Previously this was substantiated by the post-surgical healing period, which, based on the subjective experience of each particular surgeon, was defined either as one or two months (Akkuş \& Petriçli, 2018). Considering the stabilisation time of the ocular tear film, which is one of the main parameters of ocular surface homeostasis, the data obtained within the framework of this study allow one to provide an argumentbased substantiation of why one month after surgery is the optimum time required to avoid undesirable refraction errors during the selection of eyeglass lenses. 
During the development of this work, as well as during the process of literature analysis, the conclusion was made that studies researching the effect of osmolarity on the precision of the selection of eyeglass lenses are lacking. As it is often the case, new ideas of promising research directions are generated during the work process. One of the future objectives aimed at the expansion of the issue in question involves in-depth investigation of the link between tear hyperosmolarity with the variability of refraction results in eyeglass lens calculations.

The review of the results and analysis of tear film osmolarity parameters makes it clear that attention must be paid to the borderline value that separates a healthy ocular surface from an ocular surface with altered homeostasis. Based on the TearLab guidelines, the osmolarity of tears is defined as being beyond the normal limits, either where the measurement result exceeds $300 \mathrm{mOsm} / \mathrm{L}$, or where the difference in measurements between both eyes exceeds $8 \mathrm{mOsm} / \mathrm{L}$ (Piera Versura \& Campos, 2013). The aforementioned conditions bear evidence of disrupted homeostasis of the ocular surface (Szczesna-Iskander, 2016). Furthermore, TearLab guidelines define the classification of the severity degrees of the dry eye syndrome, where the osmolarity result within the limits from 300 to $320 \mathrm{mOsm} / \mathrm{L}$ is assessed as a mild condition; 320 to $340 \mathrm{mOsm} / \mathrm{L}$ as a medium severe condition, while a measurement exceeding $340 \mathrm{mOsm} / \mathrm{L}$ as a severe dry eye syndrome (Lemp et al., 2011).

Although considerable progress in the development of diagnostic equipment for osmolarity detection has been achieved over recent years, there is still no common opinion or, to be more specific - internationally admitted reference ranges or value limits that would differentiate a healthy ocular surface from an ocular surface with disrupted homeostasis and instability of the tear film (Khanal \& Millar, 2012). Based on the TearLab guidelines, this limit value is $300 \mathrm{mOsm} / \mathrm{L}$, while, in different clinical studies, this limit value varies from 
305 to $316 \mathrm{mOsm} / \mathrm{L}$, which is a rather wide range. The most commonly used, but not officially accepted limit value, is $308 \mathrm{mOsm} / \mathrm{L}$ (P. Versura et al., 2010). Exactly this limit value demonstrated the highest sensitivity in differentiating healthy eyes from eyes with dry eye syndrome in $90.7 \%$ of cases (Lemp et al., 2011) (Tomlinson et al., 2006).

Upon a detailed review of the results of the particular study, it can be concluded that, one week after the cataract surgery, the average osmolarity parameters of the tear film are altered to the degree that they exceed both the value defined by TearLab (300 mOsm/L) and worldwide unofficially recognised limit value $(308 \mathrm{mOsm} / \mathrm{L})$, as well as that the difference of osmolarity between the eyes exceeds $8 \mathrm{mOsm} / \mathrm{L}$ (10.1). These results allow the conclusion to be made that the cataract surgery disrupts ocular surface homeostasis.

During the DEWS 2007 workshop, the definition of dry eye syndrome was developed, which explains that: "Dry eye syndrome is a multifactorial disease of tears and ocular surface resulting in ocular discomfort symptoms, blurred vision, tear film instability with potential ocular surface damage. Dry eye syndrome is characterised by increased osmolarity of the tear film and inflammatory reaction of the ocular surface." (DEWS, 2007). Considering solely the definition, after the surgery cataract patients are experiencing ocular surface discomfort, as well as changes in tear film osmolarity and inflammatory reaction. Considering the above, a substantiated statement can be made that dry eye syndrome is a transitory complication during the early post-surgical period after cataract surgery in most patients (Iglesias et al., 2018).

This study has several limitations, for instance, strict exclusion criteria, which prevented the inclusion of most patients with a predisposition towards dry eye syndrome. Although there is a clear need for comprehensive research in order to provide a detailed explanation of the results obtained during this study, (for instance, a higher number of patients representing different categories, for 
instance, patients with dry eye syndrome), this study has provided results that will promote better awareness of physicians about ocular surface changes in early stages after the cataract surgery, as well as sketch the actual situation, while talking about the incidence of DES among cataract patients. Better awareness of the post-surgical period will help to better explain the situation to patients that would suffer from symptoms characteristic of dry eye syndrome. In contemporary medicine, when the quality of patient life is becoming more and more important, the possibility to forecast undesirable outcomes after cataract surgery provides advantages for both - the physician and the patient. 


\section{Conclusions of the Thesis}

- The osmolarity of the tear film of a physiologically healthy eye demonstrates a statistically significant dynamic change in the operated eye within the first month after cataract surgery.

- The tear film osmolarity in the operated eye changes from hypo-osmolar on the first day after the surgery to hyperosmolar one week after the surgery.

- The osmolarity of the tear film in the operated eye returns to the level of the results demonstrated before surgery within one month after the surgery.

- The osmolarity of the tear film in the unoperated eye does not demonstrate a statistically significant dynamic change within one month after the surgery.

- Upon the comparison of the osmolarity results of the eye tear film between the study and control groups, statistically significant changes on the day that follows the surgery and one week after the cataract surgery are demonstrated.

- With every year of life of the patient, the comparison of osmolarity before the surgery and one month after the surgery demonstrates that the osmolarity increases on average by $0.30 \mathrm{mOsm} / \mathrm{L}$.

\section{Novelty of the Thesis}

- The first data on the changes of tear film osmolarity in the early post-surgical period after cataract surgery have been obtained.

- During the performance of the study, statistically important changes in tear film osmolarity have been detected after the cataract surgery, which provides specialists with an in-depth understanding of the post-surgical healing process.

- Statistically significant results have been obtained during the study, which enables the development of forecasts regarding the required restoration time of a healthy ocular surface. 


\section{Practical Use of the Thesis}

- Performance of the tear osmolarity test is recommended before the cataract surgery to avoid post-surgical refraction errors that are associated with the implantation of the inappropriate lens due to incorrect calculations in the event of tear film hyperosmolarity.

- The performance of the tear osmolarity test is recommended one month after the surgery in pseudophakic monofocal patients to avoid the prescription and manufacturing of unsuitable glasses.

- Patients, who retained symptoms characteristic of dry eye syndrome one month after the performance of the cataract surgery, are recommended to perform the tear osmolarity test to determine the degree of ocular surface homeostasis loss and to adapt the required therapy.

\section{Prospective Directions of the Research}

- Direct effect of the cataract surgery on osmolarity measurements by excluding eye drops as an additional factor.

- Osmolarity as the affecting factor in the determining of refraction before cataract/refractive surgery, as well as in the process of eyeglass lens strength calculations.

- Changes in tear film osmolarity and the restoration thereof after the cataract surgery in the context of different patient groups (Glaucoma patients, diabetes mellitus patients, dry eye syndrome patients, regular users of eye drops).

- Restoration of osmolarity after surgery in different age groups of patients. 


\section{Approbation of the Research Work}

\section{Publications:}

- Elksnis, E. E., Laganovska, G., Erts, R. Tear osmolarity during the first postoperative month after cataract surgery. Proceedings of the Latvian Academy of Sciences. Section B. Natural, Exact, and Applied Sciences. 2021, Volume 75, Issue 5. 350-356.

- Elksnis, E., Vanags, J., Elksne, E., Gertners, O., Laganovska, G. Isolated posterior capsule rupture after blunt eye injury. Clin Case Rep. 2021, Volume 00, 1-4.

- Elksnis, Ē., Lāze, I., Erts, R., Laganovska, G. Tear osmolarity after cataract surgery. Journal of Current Ophthalmology. March 2019, Volume 31, Issue 1. 31-35.

- Elksnis, Ē., Lāce, I. Correlation between visual field functional and optic nerve disc structural damage of patients with glaucoma. Journal Acta Chirurgica latviensis. Year 2015, Volume 1. 46-49.

- Dručka, E., Elksnis, Ē., Šepetiene, S., Ozoliņ̌s, A. Bilateral peripapillary choroidal neovascularization associated with age-related macular degeneration: a case report. Journal Acta Chirurgica latviensis. Year 2020, Volume 18. 22-24.

\section{Poster Presentations at Conferences:}

- Elksnis, E. Tear osmolarity before and after cataract surgery. 29 September - 2 October. 2016. DOG 2016.

- Elksnis, E. Tear osmolarity before and after cataract surgery. 10-12 February. 2017. ESCRS XXI winter meeting.

- Elksnis, E. Tear osmolarity of students with contact lenses. 10-13 June. 2017. SOE 2017.

- Elksnis, E. Antihypertensive therapy effect on tear osmolarity during early postoperative period after cataract surgery. 7-11 October. 2017. ESCRS XXXV.

\section{Reports at Conferences:}

- Elksnis, E. Tear osmolarity changes after eye surgery. 29 April. 2017. Baltic Eye Surgeons Talk Show (BEST vol.5).

- Elksnis, $\overline{\mathrm{E}}$. The correlation between tear osmolarity, reflex tear flow and subjective symptoms of the dry eye disease in early postoperative period after cataract surgery. 10-13 June. 2017. SOE 2017.

- Elksnis, $\overline{\mathrm{E}}$. Tear osmolarity changes of open angle glaucoma patients after cataract surgery. 28 June - 1 July. 2017. VII World Glaucoma Congress. 
- Elksnis, E. Tear osmolarity of Glaucoma Patients after cataract surgery. 16 - 19 June. 2018. WOC 2018. 


\section{References}

1. Adeeb M Rushdi, U. (2018). The Unsatisfied Patient after Cataract Surgery Ocular Surface Disease as a Major Contributor! International Journal of Ophthalmology and Clinical Research, 5(4). https://doi.org/10.23937/2378-346X/1410095

2. Akkuş, Ö. G., \& Petriçli, I. S. (2018). Comparison of visual outcomes and reading performance after bilateral implantation of multifocal intraocular lenses with bilateral monofocal intraocular lenses. International Ophthalmology, 38(3), 1011-1019. https://doi.org/10.1007/s10792-017-0552-0

3. Alves, M., Reinach, P. S., Paula, J. S., Vellasco e Cruz, A. A., Bachette, L., Faustino, J., Aranha, F. P., Vigorito, A., de Souza, C. A., \& Rocha, E. M. (2014). Comparison of diagnostic tests in distinct well-defined conditions related to dry eye disease. PloS One, 9(5), e97921. https://doi.org/10.1371/journal.pone.0097921

4. Aristodemou, P., Knox Cartwright, N. E., Sparrow, J. M., \& Johnston, R. L. (2011a). Formula choice: Hoffer Q, Holladay 1, or SRK/T and refractive outcomes in 8108 eyes after cataract surgery with biometry by partial coherence interferometry. Journal of Cataract and Refractive Surgery, 37(1), 63-71. https://doi.org/10.1016/ j.jcrs.2010.07.032

5. Aristodemou, P., Knox Cartwright, N. E., Sparrow, J. M., \& Johnston, R. L. (2011b). Intraocular lens formula constant optimization and partial coherence interferometry biometry: Refractive outcomes in 8108 eyes after cataract surgery. Journal of Cataract and Refractive Surgery, 37(1), 50-62. https://doi.org/10.1016/ j.jcrs.2010.07.037

6. Astrom, S., \& Linden, C. (2007). Incidence and prevalence of pseudoexfoliation and open-angle glaucoma in northern Sweden: I. Baseline report. Acta Ophthalmologica Scandinavica, 85(8), 828-831. https://doi.org/10.1111/j.1600-0420.2007.00992.x

7. Baenninger, P. B., Voegeli, S., Bachmann, L. M., Faes, L., Iselin, K., Kaufmann, C., \& Thiel, M. A. (2018). Variability of Tear Osmolarity Measurements With a Pointof-Care System in Healthy Subjects-Systematic Review. Cornea, 37(7), 938-945. https://doi.org/10.1097/ICO.0000000000001562

8. Béatrice Cochener-Lamard. (2019). Tear Film Instability: Aetiology, Incidence and Ipact on Outcomes. EuroTimes. Supplement, 2. https://www.eurotimes.org/wpcontent/uploads/2019/11/OSD_Supplement_Nov2019-Press-Quality.pdf

9. Becker, C., Schneider, C., Aballéa, S., Bailey, C., Bourne, R., Jick, S., \& Meier, C. (2018). Cataract in patients with diabetes mellitus - incidence rates in the UK and risk factors. Eye, 32(6), 1028-1035. https://doi.org/10.1038/s41433-017-0003-1 
10. Bourne, R. R. A., Jonas, J. B., Bron, A. M., Cicinelli, M. V., Das, A., Flaxman, S. R., Friedman, D. S., Keeffe, J. E., Kempen, J. H., Leasher, J., Limburg, H., Naidoo, K., Pesudovs, K., Peto, T., Saadine, J., Silvester, A. J., Tahhan, N., Taylor, H. R., Varma, R., Resnikoff, S.(2018). Prevalenceand causes of vision loss in highincome countries and in Eastern and Central Europe in 2015: magnitude, temporal trends and projections. British Journal of Ophthalmology, 102(5), 575-585. https://doi.org/10.1136/bjophthalmol-2017-311258

11. Bunya, V. Y., Langelier, N., Chen, S., Pistilli, M., Vivino, F. B., \& Massaro-Giordano, G. (2013). Tear osmolarity in Sjögren syndrome. Cornea, 32(7), 922-927. https://doi.org/10.1097/ICO.0b013e31827e2a5e

12. Cha, S.-H., Lee, J.-S., Oum, B.-S., \& Kim, C.-D. (2004). Corneal epithelial cellular dysfunction from benzalkonium chloride (BAC) in vitro. Clinical and Experimental Ophthalmology, 32(2), 180-184. https://doi.org/10.1111/j.1442-9071.2004.00782.x

13. Chen, S. P., Massaro-Giordano, G., Pistilli, M., Schreiber, C. A., \& Bunya, V. Y. (2013). Tear osmolarity and dry eye symptoms in women using oral contraception and contact lenses. Cornea, 32(4), 423-428. https://doi.org/10.1097/ ICO.0b013e3182662390

14. Chuang, J., Shih, K. C., Chan, T. C., Wan, K. H., Jhanji, V., \& Tong, L. (2017). Preoperative optimization of ocular surface disease before cataract surgery. Journal of Cataract and Refractive Surgery, 43(12), 1596-1607. https://doi.org/ 10.1016/j.jcrs.2017.10.033

15. Comez, A. T., Tufan, H. A., Kocabiyik, O., \& Gencer, B. (2013). Effects of lubricating agents with different osmolalities on tear osmolarity and other tear function tests in patients with dry eye. Current Eye Research, 38(11), 1095-1103. https://doi.org/ 10.3109/02713683.2013.806670

16. Cooke, D. L., \& Cooke, T. L. (2016). Comparison of 9 intraocular lens power calculation formulas. Journal of Cataract and Refractive Surgery, 42(8), 1157-1164. https://doi.org/10.1016/j.jcrs.2016.06.029

17. Craig, J. P., Nichols, K. K., Akpek, E. K., Caffery, B., Dua, H. S., Joo, C.-K., Liu, Z., Nelson, J. D., Nichols, J. J., Tsubota, K., \& Stapleton, F. (2017). TFOS DEWS II Definition and Classification Report. The Ocular Surface, 15(3), 276-283. https://doi.org/10.1016/j.jtos.2017.05.008

18. Davies, I., Williams, A. M., \& Muir, K. W. (2017). Aids for eye drop administration. Survey of Ophthalmology, 62(3), 332-345. https://doi.org/10.1016/ j.survophthal.2016.12.009

19. Davis, G. (2016). The Evolution of Cataract Surgery. Missouri Medicine, 113(1), 58-62. https://pubmed.ncbi.nlm.nih.gov/27039493

20. DEWS. (2007). The definition and classification of dry eye disease: report of the Definition and Classification Subcommittee of the International Dry Eye WorkShop (2007). The Ocular Surface, 5(2), 75-92. https://doi.org/10.1016/ s1542-0124(12)70081-2 
21. Di Tommaso, C., Valamanesh, F., Miller, F., Furrer, P., Rodriguez-Aller, M., BeharCohen, F., Gurny, R., \& Moller, M. (2012). A novel cyclosporin a aqueous formulation for dry eye treatment: in vitro and in vivo evaluation. Investigative Ophthalmology \& Visual Science, 53(4), 2292-2299. https://doi.org/10.1167/ iovs.11-8829

22. Djalilian, A. R. (Ed.). (2018). Ocular Surface Disease. Springer International Publishing. https://doi.org/10.1007/978-3-319-15823-5

23. Eaglstein, W. H. (1989). Wound healing and aging. Clinics in Geriatric Medicine, 5(1), 183-188. http://www.ncbi.nlm.nih.gov/pubmed/2645996

24. Epitropoulos, A. T., Matossian, C., Berdy, G. J., Malhotra, R. P., \& Potvin, R. (2015). Effect of tear osmolarity on repeatability of keratometry for cataract surgery planning. Journal of Cataract and Refractive Surgery, 41(8), 1672-1677. https://doi.org/ 10.1016/j.jcrs.2015.01.016

25. Erdogan, H., Arici, D. S., Toker, M. I., Arici, M. K., Fariz, G., \& Topalkara, A. (2006). Conjunctival impression cytology in pseudoexfoliative glaucoma and pseudoexfoliation syndrome. Clinical \& Experimental Ophthalmology, 34(2), 108-113. https://doi.org/10.1111/j.1442-9071.2006.01168.x

26. ESCRS. (2007). Prophylaxis of postoperative endophthalmitis following cataract surgery: results of the ESCRS multicenter study and identification of risk factors. Journal of Cataract and Refractive Surgery, 33(6), 978-988. https://doi.org/ 10.1016/j.jcrs.2007.02.032

27. Fontana, L., Coassin, M., Iovieno, A., Moramarco, A., \& Cimino, L. (2017). Cataract surgery in patients with pseudoexfoliation syndrome: current updates. Clinical Ophthalmology, Volume 11, 1377-1383. https://doi.org/10.2147/OPTH.S142870

28. Foster, A. (Ed.). (2000). Vision 2020: the cataract challenge. Community Eye Health, 13(34), 17-19. https://pubmed.ncbi.nlm.nih.gov/17491949

29. Gale, R. P., Saldana, M., Johnston, R. L., Zuberbuhler, B., \& McKibbin, M. (2009). Benchmark standards for refractive outcomes after NHS cataract surgery. Eye, 23(1), 149-152. https://doi.org/10.1038/sj.eye.6702954

30. Gerstein, A. D., Phillips, T. J., Rogers, G. S., \& Gilchrest, B. A. (1993). Wound healing and aging. Dermatologic Clinics, 11(4), 749-757. http://www.ncbi.nlm.nih.gov/pubmed/8222358

31. Gonzalez-Mesa, A., Moreno-Arrones, J. P., Ferrari, D., \& Teus, M. A. (2016). Role of Tear Osmolarity in Dry Eye Symptoms After Cataract Surgery. American Journal of Ophthalmology, 170, 128-132. https://doi.org/10.1016/j.ajo.2016.08.002

32. Gupta, P. K., Drinkwater, O. J., VanDusen, K. W., Brissette, A. R., \& Starr, C. E. (2018). Prevalence of ocular surface dysfunction in patients presenting for cataract surgery evaluation. Journal of Cataract and Refractive Surgery, 44(9), 1090-1096. https://doi.org/10.1016/j.jcrs.2018.06.026 
33. He, Y., Li, J., Zhu, J., Jie, Y., Wang, N., \& Wang, J. (2017). The improvement of dry eye after cataract surgery by intraoperative using ophthalmic viscosurgical devices on the surface of cornea: The results of a consort-compliant randomized controlled trial. Medicine, 96(50), e8940-e8940. https://doi.org/10.1097/MD.0000000000008940

34. Holland, E. J., Whitley, W. O., Sall, K., Lane, S. S., Raychaudhuri, A., Zhang, S. Y., \& Shojaei, A. (2016). Lifitegrast clinical efficacy for treatment of signs and symptoms of dry eye disease across three randomized controlled trials. Current Medical Research and Opinion, 32(10), 1759-1765. https://doi.org/10.1080/ 03007995.2016.1210107

35. Holland, E., Lane, S., Horn, J. D., Ernest, P., Arleo, R., \& Miller, K. M. (2010). The AcrySof Toric Intraocular Lens in Subjects with Cataracts and Corneal Astigmatism. Ophthalmology, 117(11), 2104-2111. https://doi.org/10.1016/ j.ophtha.2010.07.033

36. Iester, M., Orsoni, G. J., Gamba, G., Taffara, M., Mangiafico, P., Giuffrida, S., \& Rolando, M. (2000). Improvement of the ocular surface using hypotonic $0.4 \%$ hyaluronic acid drops in keratoconjunctivitis sicca. Eye (London, England), 14(Pt 6), 892-898. https://doi.org/10.1038/eye.2000.244

37. Iglesias, E., Sajnani, R., Levitt, R. C., Sarantopoulos, C. D., \& Galor, A. (2018). Epidemiology of Persistent Dry Eye-Like Symptoms After Cataract Surgery. Cornea, 37(7), 893-898. https://doi.org/10.1097/ICO.0000000000001491

38. Ipek, T., Recchioni, A., Thethy, J.-S., Hartwig, A., \& O'Donnell, C. (2018). Tear osmolarity and refractive surgery. Contact Lens and Anterior Eye, 41, S79. https://doi.org/10.1016/j.clae.2018.03.122

39. Ishrat, S., Nema, N., \& Chandravanshi, S. C. L. (2019). Incidence and pattern of dry eye after cataract surgery. Saudi Journal of Ophthalmology: Official Journal of the Saudi Ophthalmological Society, 33(1), 34-40. https://doi.org/10.1016/ j.sjopt.2018.10.009

40. Ito, M., \& Shimizu, K. (2009). Reading ability with pseudophakic monovision and with refractive multifocal intraocular lenses: Comparative study. Journal of Cataract and Refractive Surgery, 35(9), 1501-1504. https://doi.org/10.1016/j.jcrs.2009.03.051

41. Jain, S., Rajshekar, K., Aggarwal, A., Chauhan, A., \& Gauba, V. K. (2019). Effects of cataract surgery and intra-ocular lens implantation on visual function and quality of life in age-related cataract patients: a systematic review protocol. Systematic Reviews, 8(1), 204. https://doi.org/10.1186/s13643-019-1113-6

42. Jones, P. L., \& Millman, A. (1990). Wound healing and the aged patient. The Nursing Clinics of North America, 25(1), 263-277. http://www.ncbi.nlm.nih.gov/ pubmed/2179892

43. Julio, G., Lluch, S., Pujol, P., Alonso, S., \& Merindano, D. (2012). Tear osmolarity and ocular changes in pterygium. Cornea, 31(12), 1417-1421. https://doi.org/ 10.1097/ICO.0b013e318259c934 
44. Khanal, S., \& Millar, T. J. (2012). Barriers to clinical uptake of tear osmolarity measurements. British Journal of Ophthalmology, 96(3), 341-344. https://doi.org/ 10.1136/bjo.2011.202754

45. Kohli, P., Arya, S. K., Raj, A., \& Handa, U. (2019). Changes in ocular surface status after phacoemulsification in patients with senile cataract. International Ophthalmology, 39(6), 1345-1353. https://doi.org/10.1007/s10792-018-0953-8

46. Kozobolis, V. P., Christodoulakis, E. V, Naoumidi, I. I., Siganos, C. S., Detorakis, E. T., \& Pallikaris, L. G. (2004). Study of conjunctival goblet cell morphology and tear film stability in pseudoexfoliation syndrome. Graefe's Archive for Clinical and Experimental Ophthalmology = Albrecht von Graefes Archiv Fur Klinische Und Experimentelle Ophthalmologie, 242(6), 478-483. https://doi.org/10.1007/s00417004-0865-3

47. Labbe, A., Terry, O., Brasnu, E., Van Went, C., \& Baudouin, C. (2012). Tear film osmolarity in patients treated for glaucoma or ocular hypertension. Cornea, 31(9), 994-999. https://doi.org/10.1097/ICO.0b013e31823f8cb6

48. Lagrasta, J. M. de S., Allemann, N., Scapucin, L., Moeller, C. T. de A., Ohkawara, L. E., Melo Jr., L. A. S., Soriano, E. S., \& Casanova, F. H. (2009). Clinical results in phacoemulsification using the SRK/T formula. Arquivos Brasileiros de Oftalmologia, 72(2), 189-193. https://doi.org/10.1590/S0004-27492009000200011

49. Lee, E. S., Lee, S. Y., Jeong, S. Y., Moon, Y. S., Chin, H. S., Cho, S. J., \& Oh, J. H. (2005). Effect of postoperative refractive error on visual acuity and patient satisfaction after implantation of the Array multifocal intraocular lens. Journal of Cataract and Refractive Surgery, 31(10), 1960-1965. https://doi.org/10.1016/j.jcrs.2005.03.062

50. Lee, J.-E., Kim, N. M., Yang, J. W., Kim, S. J., Lee, J. S., \& Lee, J. E. (2014). A randomised controlled trial comparing a thermal massager with artificial teardrops for the treatment of dry eye. British Journal of Ophthalmology, 98(1), 46-51. https://doi.org/10.1136/bjophthalmol-2013-303742

51. Lee, S.-Y., Wong, T. T., Chua, J., Boo, C., Soh, Y. F., \& Tong, L. (2013). Effect of chronic anti-glaucoma medications and trabeculectomy on tear osmolarity. Eye (London, England), 27(10), 1142-1150. https://doi.org/10.1038/eye.2013.144

52. Lemp, M. A., Bron, A. J., Baudouin, C., Benitez Del Castillo, J. M., Geffen, D., Tauber, J., Foulks, G. N., Pepose, J. S., \& Sullivan, B. D. (2011). Tear osmolarity in the diagnosis and management of dry eye disease. American Journal of Ophthalmology, 151(5), 792-798.e1. https://doi.org/10.1016/j.ajo.2010.10.032

53. Liu, X., Gu, Y., \& Xu, Y. (2008). Changes of tear film and tear secretion after phacoemulsification in diabetic patients. Journal of Zhejiang University. Science. B, 9(4), 324-328. https://doi.org/10.1631/jzus.B0710359

54. Liu, Y.-C., Wilkins, M., Kim, T., Malyugin, B., \& Mehta, J. S. (2017). Cataracts. The Lancet, 390(10094), 600-612. https://doi.org/10.1016/S0140-6736(17)30544-5 
55. Lum, E., Corbett, M. C., \& Murphy, P. J. (2019). Corneal Sensitivity After Ocular Surgery. Eye \& Contact Lens: Science \& Clinical Practice, 45(4), 226-237. https://doi.org/10.1097/ICL.0000000000000543

56. Malozhen, S. A., Trufanov, S. V, \& Krakhmaleva, D. A. (2017). [Pterygium: etiology, pathogenesis, treatment]. Vestnik oftalmologii, 133(5), 76-83. https://doi.org/ 10.17116/oftalma2017133576-83

57. Miller, W. L., Doughty, M. J., Narayanan, S., Leach, N. E., Tran, A., Gaume, A. L., \& Bergmanson, J. P. G. (2004). A comparison of tear volume (by tear meniscus height and phenol red thread test) and tear fluid osmolality measures in non-lens wearers and in contact lens wearers. Eye \& Contact Lens, 30(3), 132-137. https://doi.org/ 10.1097/01.icl.0000138714.96401.2b

58. Montani, G. (2013). Intrasubject tear osmolarity changes with two different types of eyedrops. Optometry and Vision Science: Official Publication of the American Academy of Optometry, 90(4), 372-377. https://doi.org/10.1097/ OPX.0b013e318288bdbe

59. Muselier-Mathieu, A., Bron, A. M., Mathieu, B., Souchier, M., Brignole-Baudouin, F., Acar, N., Bretillon, L., \& Creuzot-Garcher, C. (2014). Ocular surface assessment in soft contact lens wearers; the contribution of tear osmolarity among other tests. Acta Ophthalmologica, 92(4), 364-369. https://doi.org/10.1111/aos.12103

60. Nagelschmidt, M., \& Engelhardt, G. H. (1983). [Age-related problems of wound healing]. Aktuelle Gerontologie, 13(3), 108-110. http://www.ncbi.nlm.nih.gov/ pubmed/6135356

61. Narayanan, S. (2011). Osmolarity: A Diagnostic Test for Dry Eye. Review of Optomtery. https://www.reviewofoptometry.com/article/osmolarity-a-diagnostictest-for-dry-eye

62. Nichols, J. J., \& Sinnott, L. T. (2006). Tear film, contact lens, and patient-related factors associated with contact lens-related dry eye. Investigative Ophthalmology \& Visual Science, 47(4), 1319-1328. https://doi.org/10.1167/iovs.05-1392

63. Norregaard, J. C., Bernth-Petersen, P., Alonso, J., Andersen, T. F., \& Anderson, G. F. (2003). Visual functional outcomes of cataract surgery in the United States, Canada, Denmark, and Spain: report of the International Cataract Surgery Outcomes Study. Journal of Cataract and Refractive Surgery, 29(11), 2135-2142. https://doi.org/ 10.1016/s0886-3350(03)00340-7

64. Oh, T., Jung, Y., Chang, D., Kim, J., \& Kim, H. (2012). Changes in the tear film and ocular surface after cataract surgery. Japanese Journal of Ophthalmology, 56(2), 113118. https://doi.org/10.1007/s10384-012-0117-8

65. Oncel, B. A., Pinarci, E., \& Akova, Y. A. (2012). Tear osmolarity in unilateral pseudoexfoliation syndrome. Clinical \& Experimental Optometry, 95(5), 506-509. https://doi.org/10.1111/j.1444-0938.2011.00683.x 
66. Oncel, B., Pinarci, E., \& Akova, Y. (2012). The Tear Osmolarity Changes After Cataract Surgery. Turk Oftalmoloiji Dergisi, 42, 35-37. https://doi.org/ 10.4274/tjo.42.70783

67. Park, Y., Hwang, H. Bin, \& Kim, H. S. (2016). Observation of Influence of Cataract Surgery on the Ocular Surface. PLOS ONE, 11(10), e0152460. https://doi.org/ 10.1371/journal.pone.0152460

68. Potvin, R., Makari, S., \& Rapuano, C. J. (2015). Tear film osmolarity and dry eye disease: a review of the literature. Clinical Ophthalmology (Auckland, N.Z.), 9, 2039-2047. https://doi.org/10.2147/OPTH.S95242

69. Radner, W., Radner, S., Raunig, V., \& Diendorfer, G. (2014). Reading performance of monofocal pseudophakic patients with and without glasses under normal and dim light conditions. Journal of Cataract and Refractive Surgery, 40(3), 369-375. https://doi.org/10.1016/j.jcrs.2013.08.054

70. Röggla, V., Leydolt, C., Schartmüller, D., Schwarzenbacher, L., Meyer, E., AbelaFormanek, C., \& Menapace, R. (2021). Influence of Artificial Tears on Keratometric Measurements in Cataract Patients. American Journal of Ophthalmology, 221, 1-8. https://doi.org/https://doi.org/10.1016/j.ajo.2020.08.024

71. Sagdik, H. M., Ugurbas, S. H., Can, M., Tetikoglu, M., Ugurbas, E., Ugurbas, S. C., Alpay, A., \& Ucar, F. (2013). Tear film osmolarity in patients with diabetes mellitus. Ophthalmic Research, 50(1), 1-5. https://doi.org/10.1159/000345770

72. Sullivan, B. D., Crews, L. A., Sonmez, B., de la Paz, M. F., Comert, E., Charoenrook, V., de Araujo, A. L., Pepose, J. S., Berg, M. S., Kosheleff, V. P., \& Lemp, M. A. (2012). Clinical utility of objective tests for dry eye disease: variability over time and implications for clinical trials and disease management. Cornea, 31(9), 1000-1008. https://doi.org/10.1097/ICO.0b013e318242fd60

73. Sullivan, B. D., Whitmer, D., Nichols, K. K., Tomlinson, A., Foulks, G. N., Geerling, G., Pepose, J. S., Kosheleff, V., Porreco, A., \& Lemp, M. A. (2010). An objective approach to dry eye disease severity. Investigative Ophthalmology \& Visual Science, 51(12), 6125-6130. https://doi.org/10.1167/iovs.10-5390

74. Sutu, C., Fukuoka, H., \& Afshari, N. A. (2016). Mechanisms and management of dry eye in cataract surgery patients. Current Opinion in Ophthalmology, 27(1), 24-30. https://doi.org/10.1097/ICU.0000000000000227

75. Szczesna-Iskander, D. H. (2016). Measurement variability of the TearLab Osmolarity System. Contact Lens and Anterior Eye, 39(5), 353-358. https://doi.org/ 10.1016/j.clae.2016.06.006

76. tearlab.com. (n.d.). TearLab ${ }^{T M}$ Osmolarity System Clinical Utility Guide. https://www.tearlab.com/

77. Tomlinson, A., Khanal, S., Ramaesh, K., Diaper, C., \& McFadyen, A. (2006). Tear film osmolarity: determination of a referent for dry eye diagnosis. Investigative Ophthalmology \& Visual Science, 47(10), 4309-4315. https://doi.org/10.1167/ iovs.05-1504 
78. Tomlinson, A., Madden, L. C., \& Simmons, P. A. (2013). Effectiveness of dry eye therapy under conditions of environmental stress. Current Eye Research, 38(2), 229-236. https://doi.org/10.3109/02713683.2012.757323

79. Trattler, W. B., Majmudar, P. A., Donnenfeld, E. D., McDonald, M., Stonecipher, K. C., \& Goldberg, D. (2017). The Prospective Health Assessment of Cataract Patients\&rsquo; Ocular Surface (PHACO) study: the effect of dry eye. Clinical Ophthalmology, Volume 11, 1423-1430. https://doi.org/10.2147/OPTH.S120159

80. Versura, P., Profazio, V., \& Campos, E. C. (2010). Performance of Tear Osmolarity Compared to Previous Diagnostic Tests for Dry Eye Diseases. Current Eye Research, 35(7), 553-564. https://doi.org/10.3109/02713683.2010.484557

81. Versura, Piera, \& Campos, E. C. (2013). TearLab ® Osmolarity System for diagnosing dry eye. Expert Review of Molecular Diagnostics, 13(2), 119-129. https://doi.org/10.1586/erm.12.142

82. Zhang, X., M, V. J., Qu, Y., He, X., Ou, S., Bu, J., Jia, C., Wang, J., Wu, H., Liu, Z., \& Li, W. (2017). Dry Eye Management: Targeting the Ocular Surface Microenvironment. International Journal of Molecular Sciences, 18(7), 1398. https://doi.org/10.3390/ijms18071398 


\section{Acknowledgements}

I would like to deeply thank my family and wife Eva for the support, understanding and encouragement, when it was needed most. I am thankful to my parents, who have always served as a model to look up to.

Acknowledgements to my brother for sports-like excitement, which helped to reach the set objectives. To my grandmother for human sincerity.

I am thankful to Professor Guna Laganovska for the opportunity that she provided and the testing of my character.

I am thankful to my colleagues and work mates for support in the daily work routine. 